\title{
Evidence that non-pathogenic microorganisms drive sea star wasting disease through boundary layer oxygen diffusion limitation
}

Citlalli A. Aquino ${ }^{1 *}$, Ryan M. Besemer ${ }^{2 *}$, Christopher M. DeRito ${ }^{3}$, Jan Kocian ${ }^{4}$, Ian R. Porter ${ }^{5}$, Peter Raimondi ${ }^{6}$, Jordan E. Rede ${ }^{3}$, Lauren M. Schiebelhut ${ }^{7}$, Jed P. Sparks ${ }^{8}$, John P. Wares ${ }^{9}$, Ian Hewson $^{3 \dagger}$

${ }^{1}$ Department of Biology, Estuary and Ocean Science Center, San Francisco State University, Romberg Tiburon Campus, 3150 Paradise Dr, Tiburon CA 94132 USA

${ }^{2}$ Center for Marine Science, University of North Carolina Wilmington, 5600 Marvin K Moss Ln, Wilmington, NC 28409 USA

${ }^{3}$ Department of Microbiology, Cornell University, Wing Hall 403, Ithaca NY 14853 USA

${ }^{4}$ Unaffiliated Researcher, Leland WA 98376 USA

${ }^{5}$ Department of Clinical Sciences, College of Veterinary Medicine, Cornell University, 602

Tower Rd, Ithaca, NY 14853 USA

${ }^{6}$ Institute of Marine Sciences, Department of Ecology \& Evolutionary Biology, University of California Santa Cruz, 1156 High Street, Santa Cruz, CA 95064 USA

${ }^{7}$ Life and Environmental Sciences, University of California Merced, 5200 North Lake Rd. Merced, CA 95343 USA

${ }^{8}$ Department of Ecology \& Evolutionary Biology, Cornell University, Corson Hall, Ithaca NY 14853 USA

${ }^{9}$ Department of Genetics, University of Georgia, 30602120 W Green St, Athens, GA 30602 USA

*Denotes equal author contribution

${ }^{\dagger}$ Corresponding Author: hewson@cornell.edu 


\section{ABSTRACT}

2 Sea star wasting disease describes a condition affecting asteroids that resulted in significant

3 Northeastern Pacific population decline following a mass mortality event in 2013. The etiology

4 of sea star wasting is unresolved. We hypothesized that asteroid wasting is a sequela of microbial

5 organic matter remineralization near respiratory surfaces which leads to boundary layer oxygen

6 diffusion limitation (BLODL). Wasting lesions were induced in Pisaster ochraceus by

7 enrichment with a variety of organic matter (OM) sources and by experimentally reduced oxygen

8 conditions. Microbial assemblages inhabiting tissues and at the asteroid-water interface bore

9 signatures of copiotroph proliferation before wasting onset, followed by the proliferation of

10 putatively facultative and strictly anaerobic taxa. These results together illustrate that suboxic

11 conditions at the animal-water interface may be established by heterotrophic bacterial activity in

12 response to organic matter loading. Wasting susceptibility was significantly and positively

13 correlated with rugosity, a key determinant of boundary layer thickness. At a semi-continuously

14 monitored field site (Langley Harbor), wasting predictably occurred at annual peak or decline in

15 phytoplankton biomass over 5 years, suggesting that primary production-derived OM may

16 contribute to BLODL. Finally, wasting individuals from 2013 - 2014 bore stable isotopic

17 signatures reflecting anaerobic processes which suggests that this phenomenon may have affected asteroids during mass mortality. The impacts of BLODL may be more pronounced under higher temperatures due to lower $\mathrm{O}_{2}$ solubility, in more rugose asteroid species due to restricted hydrodynamic flow, and in larger specimens due to their lower surface area to volume ratios which affects diffusive respiratory potential. Moreover, our results demonstrate that marine invertebrate disease may result from heterotrophic microbial activity that occurs adjacent to respiratory tissues, which raises important questions about the etiology of marine diseases in other benthic taxa. 


\section{INTRODUCTION}

Sea star wasting (SSW) disease describes a suite of clinical signs in asteroids including loss of turgor, arm twisting, epidermal ulceration, limb autotomy, and death. The condition gained prominence in 2013 when it caused mass mortality of $>20$ asteroid species in the Northeastern Pacific (Hewson et al., 2014) with continuous observations since (Miner et al., 2018;Jaffe et al., 2019). However, lesions compatible with SSW in various asteroid species have been reported since at least 1896 in the Eastern US (Mead, 1898), and at many locations globally (reviewed in Hewson et al., 2019). The cause of SSW is unresolved. Early reports that SSW was associated with a densovirus (Hewson et al., 2014) were refuted by subsequent investigation that failed to show a consistent association between the virus and presence of disease (Hewson et al., 2018), and recent description of persistent and phylogenetically widespread infection by related densoviruses (Jackson et al., 2020a;Jackson et al., 2020b) suggest this virus to be a component of normal microbiome. Furthermore, wasting is not consistently associated with any bacterial or microbial eukaryotic organism (Hewson et al., 2018). Environmental conditions, including elevated water temperatures (Eisenlord et al., 2016;Kohl et al., 2016), lower water temperatures and higher $\mathrm{pCO}_{2}$ (Menge et al., 2016), and meteorological conditions (Hewson et al., 2018) correspond with wasting at distinct locations. Recent modelling studies suggest repeated sea surface temperature anomalies may correlate with wasting (Aalto et al., 2020). Reports of SSW spread between adjacent geographic locations, through public aquarium intakes, and challenge experiments with tissue homogenates suggested a transmissible etiology (Hewson et al., 2014;Bucci et al., 2017). However, there is a lack of mechanistic understanding how SSW is generated in affected individuals.

Here we provide convergent evidence that asteroid wasting is a sequela of boundary layer oxygen diffusion limitation (BLODL; Fig. 1). In this model, elevated organic matter (OM) concentrations stimulate the growth of copiotrophic microorganisms adjacent to animal surfaces, driving down dissolved $\mathrm{O}_{2}$ concentrations and causing suboxic conditions at the animal-seawater interface within the diffusive boundary layer. Over time, these conditions do not meet respiratory $\mathrm{O}_{2}$ demand of tissues, resulting in their damage and decomposition, which further enriches nearasteroid pools of organic material. This in turn results in the proliferation of anaerobic taxa on and within tissues. Here we provide evidence for this effect through study of microbiome 
composition during organic matter amendment and as animals waste in the absence of external stimuli. Further, we demonstrate that wasting can result from suboxic water column conditions. Next, we illustrate that wasting susceptibility is related to inherent asteroid properties, including rugosity (a key physical characteristic influencing diffusive boundary layer height), animal size and respiratory demand. We explored the relationship between primary production and wasting during a 5 year time series at a field site and find significant correlation between wasting occurrence and trends in chlorophyll a, which is one potential source of OM for bacterial nutrition. Finally, we demonstrate that wasting asteroids from the 2013-2014 mass mortality event bore stable isotopic signatures that reflect anaerobic microbial processes compared to their asymptomatic sympatric counterparts.

\section{METHODS}

Gross wasting definition and general specimen characteristics: Sea star wasting (SSW) in field populations is reported to comprise a wide suite of signs, including loss of turgor (deflation), discoloration, puffiness, arm twisting/curling, limb autotomy, body wall lesions and erosions and protrusion of pyloric caeca and gonads (Hewson et al., 2014). There is currently no case definition for any species of asteroid, nor is there progression of disease signs characteristic of wasting (i.e. wasting has no pathognomic signs; Hewson et al., 2019). Because many of these disease signs are subject to observer bias, we sought to standardize occurrence of wasting between experiments and surveys. We considered wasting as the appearance of non-focal body wall lesions across all experiments. We used the time between experiment initiation and body wall lesion appearance (i.e. lesion genesis) as a standardized parameter to assess the speed of wasting. Experiments were performed where individuals were physically isolated from each other while in the same aquarium water body through plastic containers which had been punched with holes (4mm diameter) at a density of $\sim 2$ holes $\mathrm{cm}^{-2}$. However, in the May - June 2018 observation of wasting in the absence of external stimuli, individuals were identified by the unique "fingerprint" of apical circlet paxillae and spines and were not physically separated from each other. In all experiments, lesion position was standardized by clockwise naming of rays from the madreporite. Individual asteroids were considered dead when tube feet did not move during observation for 30s, or when all limbs autotomized away from the central disc. The mass 
of individuals was determined using a top pan balance, and each ray measured from tip to the center of central disc using a ruler or calipers.

Impact of organic matter enrichment on wasting in Pisaster ochraceus: We examined the impact of OM enrichment on asteroid wasting to test whether enrichment caused bacterial abundance and composition shifts consistent with the boundary layer oxygen diffusion limitation (BLODL) hypothesis. Twenty P. ochraceus (mass $303 \pm 26$ g) were obtained from the jetty at Bodega Bay in July 2019 and transported to the Bodega Bay Marine Lab (UC Davis), where they were placed in flow-through large volume sea tables for $7 \mathrm{~d}$ prior to commencement of the experiment. Asteroids were placed individually into baskets and suspended in each of 4 sea tables with flow rates of $60 \pm 15 \mathrm{~mL} \mathrm{~s}^{-1}$. A dense $\left(\sim 10^{4}\right.$ cells $\left.\mathrm{mL}^{-1}\right)$ culture of Dunaliella tertiolecta was prepared in $20 \mathrm{~L}$ artificial seawater, which was filtered onto $0.2 \mu \mathrm{m}$ Durapore filters and resuspended in $1 \mathrm{~L}$ artificial seawater. The resuspended matter was divided into $21 \mathrm{x}$ $45 \mathrm{~mL}$ aliquots and frozen prior to use. Coastal particulate OM (POM) was prepared by filtering $40 \mathrm{~L}$ seawater from the unfiltered intake pipe at Bodega Marine Laboratory through $0.2 \mu \mathrm{m}$ Durapore filters, which was then resuspended in $1 \mathrm{~L}$ seawater. This was also divided into 21 x 35 $\mathrm{ml}$ aliquots and frozen before use. Individuals ( $\mathrm{n}=5$ per treatment in separate sea tables) were

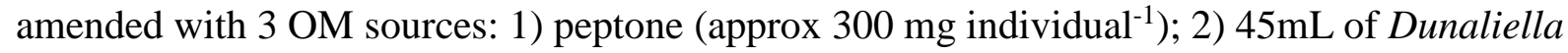
tertiolecta filtered culture; and 3) Coastal POM (6mL) daily. Individual asteroids were observed daily (aboral and ventral surface) for the presence of lesions and they were weighed. There was no significant difference in the rate of animal mass change over the course of the experiment between treatments (Fig. S1), where individuals lost $11.0 \pm 0.2 \%$ of their initial mass over the course of the experiment. Daily samples ( $2 \mathrm{~mL}$ of water) for surface bacterial abundance were withdrawn using $3 \mathrm{~mL}$ syringes which were pressed onto the aboral surface of individual stars while immersed, and preserved in 5\% formalin and kept at $4^{\circ} \mathrm{C}$ in darkness prior to processing. Surface microbial communities were sampled every 48 h by collecting a swab (sterile cottontipped, dry transport system; Puritan) from each aboral surface which were then frozen at $-20^{\circ} \mathrm{C}$ prior to processing. Microbiome compositional analyses was performed as described later in this section.

Wasting progression in the absence of external stimuli: We sought to investigate longitudinal microbiome composition over wasting progression in lesion margins and in artificial scar tissues, 
in an attempt to discern opportunistic taxa from potential pathogens. This work was performed to target epidermis-associated microorganisms which were minimally sampled (i.e. by surface scrape), and in a separate study to target body wall tissues (i.e. by transverse body wall biopsy punch). We anecdotally observed in previous work (Hewson et al., 2018) that sampling stress, especially by collection of tissues by biopsy punch, may influence wasting in aquarium studies so sought to minimize sampling before the appearance of lesions.

To examine wasting in epidermal tissues (which presumably include microorganisms inhabiting tissue surfaces as well as those beneath the epidermis and cuticle but excluding body wall and mutable collagenous tissue-associated microorganisms), we examined temporal progression in $P$. ochraceus specimens from central California collected on 19 July 2018. Six specimens (mean mass $290 \pm 54 \mathrm{~g}$ and ray length $11.2 \pm 0.9 \mathrm{~cm}$ ) were collected from the intertidal zone at

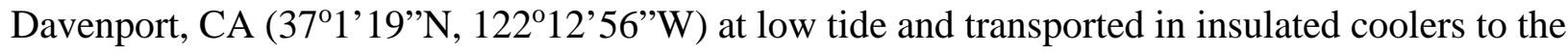
Long Marine Laboratory at UC Santa Cruz, where they were housed in flow-through aquaria (3.81 $\pm 0.05 \mathrm{~mL} \mathrm{~s}^{-1}$; mean water residence time $37 \mathrm{~min}$ ) indoors in individual containers. Individuals were maintained under these conditions for the duration of the experiment.

Temperature, salinity, and dissolved $\mathrm{O}_{2}$ were measured daily using a YSI-3000 handheld meter. After a $48 \mathrm{~h}$ acclimation period, a small scar ( $5 \mathrm{~mm}$ long) was made on a single ray using a sterile $4 \mathrm{~mm}$ biopsy punch. Individual asteroids were monitored daily for the presence of lesions (as defined above). A small tissue sample ( $3 \mathrm{~mm} \times 2 \mathrm{~mm}$ ) was taken from the margin of artificial scars using sterile $4 \mathrm{~mm}$ biopsy punches after $24 \mathrm{~h}$. New artificial scars were made on adjacent rays each day, and sampled after 24h. When lesions away from these artificial scars were observed (i.e. lesions not caused by physical scarring), their margin tissues were sampled using the same approach. All tissue samples were placed into sterile $1.2 \mathrm{~mL}$ cryovials and immediately frozen in liquid $\mathrm{N}_{2}$ or in a $-80^{\circ} \mathrm{C}$ freezer.

To examine wasting in all body wall + epidermal tissues (i.e. biopsy punch), we examined temporal progression in $P$. ochraceus specimens collected on 24 May 2018 from Davenport, CA (37¹'19’N, $122^{\circ} 12^{\prime} 56^{\prime} \mathrm{W}$ ), which were transported in an insulated container to the Long Marine Laboratory at UC Santa Cruz where they were placed into a single, flow-through sea table. The individuals were measured, weighed and photographed to fingerprint apical circlet pattern. A single biopsy punch (4 $\mathrm{mm}$ ) was retrieved from each individual and preserved in 
liquid $\mathrm{N}_{2}$. After 312 h, 10 of the 12 had lesions on their surfaces, and after $360 \mathrm{~h}$, all individuals had lesions. After 360 h, lesions were sampled by biopsy punch and preserved in liquid $\mathrm{N}_{2}$, and again at time of death, which occurred between $360 \mathrm{~h}$ and $480 \mathrm{~h}$. Because we did not capture the exact time of lesion occurrence, we restricted analysis of these individuals to samples collected at initial (T0), $360 \mathrm{~h}$ (TI - i.e. shortly after lesions had formed) and at time of death (TF).

Impact of suboxic conditions on wasting in Asterias forbesi: To test whether wasting could result from suboxic conditions, we incubated asteroids in incubations where $\mathrm{O}_{2}$ was depleted and examined surface microbiome abundance and composition. Twenty-four Asterias forbesi (mass $63 \pm 7$ g) were obtained from Bar Harbor, ME (44²5.7’ N, 68²12.0’W) on 29 June 2019 and transported in insulated coolers to the laboratory at Cornell University. There, the individuals were initially placed into a single, $320 \mathrm{~L}$ aquarium for $24 \mathrm{~h}$, before being placed into individual flow-through baskets and divided into two treatments. One large volume (230 L) sump containing artificial seawater (Instant Ocean) was set up for each treatment. One sump served as a control, while another sump was continuously sparged with medical-grade $\mathrm{N}_{2}\left(\sim 5-6 \mathrm{~L} \mathrm{~min}^{-1}\right)$ to lower $\mathrm{pO}_{2}$. Continuous flow between sump and aquarium systems was maintained by nonself-priming pumps and removed by gravity through a standpipe. $\mathrm{O}_{2}$ and temperature was continuously monitored in the experimental tanks using $\mathrm{HOBO} \mathrm{O}_{2}$ Loggers (U26; Onset).

$\mathrm{O}_{2}$ was depleted in $\mathrm{N}_{2}$-sparged sump waters $\left(5.87 \pm 0.29 \mathrm{mgL}^{-1}\right)$ compared to control incubations $\left(9.62 \pm 0.06 \mathrm{mg} \mathrm{L}^{-1}\right)$, representing a mean concentration decrease of $\sim 39 \%$. Individual asteroids were monitored daily for the gross appearance of lesions on aboral and ventral surfaces. There was no significant difference in the rate of mass change between treatments, where all individuals lost on average $30.0 \pm 6.5 \%$ of the initial mass over the course of the experiment as they were not fed (Fig. S1). At experiment initiation, surface bacterial abundance samples were taken and preserved as described above. The mass of individuals was recorded daily; stars remained without prey during the experiment. Surface microbial swabs were sampled every 48h following the approach outlined above. To reduce sampling stress on individuals, half of individuals in each treatment were biopsied (2 x 3 mm biopsy samples collected using sterile biopsy punches) on their aboral surface at experiment initiation, and then every $5 \mathrm{~d}$ until experiment termination (biopsied specimen lesion genesis time was not significantly different to non-biopsied specimen lesion genesis time). Biopsy punches (1 each) were preserved in 
RNALater or in 10\% neutral buffered formalin. Upon appearance of lesions, their margins were sampled using a $5 \mathrm{~mm}$ biopsy punch to scrape a $3 \mathrm{~mm}$ x $2 \mathrm{~mm}$ tissue sample. Additionally, a 3 mm biopsy punch was used to obtain a sample through body wall tissues on the lesion margins. Lesion margin tissues were stored at $-20^{\circ} \mathrm{C}$ until analysis.

Bacterial abundance: Bacterial abundance in suboxic and organic matter amendment experiments was determined by SYBR Gold staining and epifluorescence microscopy (Porter and Feig, 1980;Noble and Fuhrman, 1998;Shibata et al., 2006). An aliquot (1 mL) of each sample was first stained with SYBR Gold (2 $\mu \mathrm{mL}^{-1}$ of the 10,000X stock) for $2 \mathrm{~min}$, then samples were filtered through 25mm diameter $0.2 \mu \mathrm{m}$ black cyclopore filters mounted on $25 \mathrm{~mm}$ Type AA Millipore filters to even flow. The filters were removed from the backing filter, adhered to clean glass slides and mounted in $30 \mu \mathrm{L}$ of PBS:Glycerol (50:50) containing 0.1\% pphenylenediamine. The slides were visualized on an Olympus BX-51 epifluorescence microscope under blue light excitation. Over 200 cells were counted in >10 fields. Bacterial abundance was calculated by multiplying mean abundance per reticle grid by total grids per filter area, and divided by volume passed through the filter. For some samples, high background fluorescence precluded accurate counts and so are not included in downstream analyses.

Microbial assemblage analyses: Microbial assemblages inhabiting body wall samples (i.e. biopsy punch; wasting in the absence of external stimuli), lesion margins (i.e epidermal scrapes; wasting in the absence of external stimuli), and at the animal/water interface (i.e. swabs; suboxic and organic matter enrichment experiments) were examined by 16S rRNA amplicon sequencing. Nucleic acids were extracted from frozen 3mm biopsies, lesion margin scrapes, and frozen surface swabs using a Quick-DNA Fungal/Bacterial MiniPrep Kit (Zymo Research, cat\# D6005) according to the manufacturer's protocol. Bacterial DNA was quantified using a Quant-IT dsDNA Assay (Invitrogen, cat\# Q33120) in conjunction with a StepOnePlus ${ }^{\mathrm{TM}}$ Real-Time PCR system (Applied Biosystems). Bacterial community composition was examined via PCR amplification sequencing of the V4 region of the 16S rRNA gene using a modified version from Caporaso et al., 2011. Fifty $\mu$ l PCR reactions contained 1x 5PRIME HotMasterMix (QuantaBio, cat\# 2200400) and 0.1 $\mu \mathrm{M}$ each primer (515f/barcoded-806r). Template DNA quantity varied between experiments. For examining microbiome composition during wasting progression, $1 \mu \mathrm{l}$ of extract (containing from below detection limit of $0.1 \mathrm{ng}$ to $80 \mathrm{ng}$ [mean $=17 \mathrm{ng}$ ]) was used as 
PCR template. For Asterias forbesi hypoxia and Pisaster ochraceus OM enrichment, 5 pg of genomic DNA (determined by Femto Bacterial DNA Quantification Kit; Zymo Research, cat\# E2006) was used to standardize prokaryotic template amounts (Hewson, 2019). PCR products

212 from duplicate reactions were pooled for each sample and cleaned using a Mag-Bind RxnPure

213 Plus Kit (Omega Bio-tek, cat\# M1386-01). Ten ng of bacterial DNA from each sample were

214 pooled, libraries prepared using the NextFLEX prep, and sequenced on 2 lanes of Illumina MiSeq (2 x 250 paired end) at the Cornell Biotechnology Resource Center. Sequence libraries are available at QIITA under studies 12131 and 13061 and at NCBI under BioProject

Raw sequences were uploaded to QIITA and processed using the native 16S rRNA pipeline 219 (Gonzalez et al., 2018). After demultiplexing, reads were trimmed to 150 bp and sub-OTUs (sOTUs) were configured using Deblur (Amir et al., 2017). The SEPP phylogenetic tree and BIOM/FA files were downloaded from the deblur reference hit table and converted into qiime2 (v2019.10) artifacts, after which taxonomy was assigned using the Silva 132 release (Quast et al., 2012) and q2-feature-classifier plugin. All files were then imported into R (v3.6.1) using qiime2R v(0.99) (Caporaso et al., 2010) and compiled into a phyloseq (v1.28) (McMurdie and Holmes, 2013) object for downstream analyses.

Amplicon data was transformed using the PhILR (Phylogenetic Isometric Log-Ratio Transform, v1.1) package for ordination (Silverman et al., 2017). PhILR transforms compositional data (i.e., proportional, or relative data) into a new matrix of 'balances' that incorporates phylogenetic information. Here, a balance is defined as the isometric log-ratio (ILR) between two clades that share a common node. The ILR is a common tool used in compositional data analysis that transforms constrained data into an unconstrained space (i.e., Euclidean space), thereby allowing standard statistical tools to be applied. For each experiment, low abundance sOTUs were filtered 233 based on sequencing depth/evenness and a pseudocount of 0.65 was applied to all 0 counts. The

234 ILR analyses in this study do not require an even sampling depth, and therefore, count 235 normalization techniques like rarefying, which lead to a loss of information (McMurdie and 236 Holmes, 2014), were not utilized. Phyloseq (1.32.0) (McMurdie and Holmes, 2013) was used to 237 perform principal coordinate analyses (PCoA) on the Euclidean distances between PhILR 238 transformed samples, and the adonis function in the vegan package (v2.5-6) (Oksanen et al., 

2019) was used to perform a PERMANOVA on relevant PCoAs. For June 2018 Pisaster ochraceus samples, a principal coordinate analysis based on Weighted Unifrac distances (Lozupone et al., 2011) was used in lieu of the PhILR transformation due to higher explained variance from a PERMANOVA. For these samples, low abundant sOTUs were removed and the data was transformed to an even sampling depth. Multiple filtering strategies were applied to all analyses and did not affect results.

Balances were used to quantify differential abundance in order to address the issue of compositionality in amplicon data. Two approaches were used that rely on the ILR transformation. For comparisons between two categorical variables (diseased/non-diseased tissue and surface swabs from specimens immediately before lesions appear with earlier specimens), a sparse logistic regression with an $l_{1}$ penalty of $\lambda=0.15$ was applied to PhILR balances using the glmnet package v(3.0-2) (Friedman et al., 2010). For time-course experiments, the PhyloFactor package (v0.0.1) was used. PhyloFactor calculates balances in a similar fashion to PhILR, but instead of using nodes to contrast clades, Phylofactor bisects a phylogenetic tree along its edges in an iterative manner. Each iteration, or 'factor,' is regressed using a generalized linear model. Edges were maximized using the F statistic and a Kolmogorov-Smirnov test was used to break the iterations.

Additional experimental challenges of Pisaster ochraceus: We also sought further evidence of BLODL by examining wasting in context of water flow rates, desiccation stress, and challenge with tissue homogenates from a wasting specimen. $P$. ochraceus $(\mathrm{n}=24)$ were collected from Mitchell Cove, Santa Cruz (36 $\left.57.1 \mathrm{~N}, 122^{\circ} 2.51^{\prime} \mathrm{W}\right)$, on 25 June 2018 at low tide (mean mass $357 \pm 37 \mathrm{~g}$ ), and transported in a cooler to the Long Marine Laboratory. Metadata on their size and weight, along with mean flow rates in incubations and change in mass over time is provided in Table S1. The temperature in aquarium settings for all experiments was measured by Onset Hobo Spot loggers $(n=2)$ which were deployed into aquarium outflows for the first 4 days of the experiment, and after 6 days was measured using a YSI Handheld Instrument.

The impact of water flow on asteroid wasting was examined in 12 specimens. Asteroids $(\mathrm{n}=6$ each treatment) were placed into individual plastic boxes which were subject to high (7.06 \pm 0.39 $\mathrm{ml} \mathrm{s}^{-1}$; water residence time in container $\left.\sim 20 \mathrm{~min}\right)$ and low (2.84 $\pm 0.26 \mathrm{ml} \mathrm{s}^{-1}$; water residence time 50 min) flow-through rates. Temperature and salinity were monitored daily using a 
handheld YSI Probe (YSI-3000). Individuals were visually inspected daily for the presence of body wall lesions and were weighed to determine changes in their overall mass over the course of the experiment.

The experiments were performed over a 21 day period during which mean water flow-through temperatures ranged from $14.4-17.6^{\circ} \mathrm{C}$ (Fig. S2), with day-night variation of $1.8-1.9^{\circ} \mathrm{C}$. Water temperatures increased mostly between 10 and 15 days of incubation. Salinity did not vary by more than 0.2 over the course of the experiment. Additionally, we deployed two loggers into the

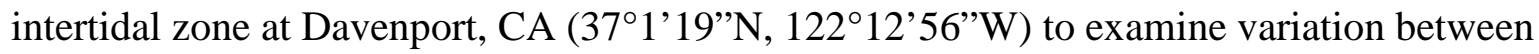
experimental temperature conditions and conditions experienced by asteroids at the collection site. In contrast to experimental flow-through systems, field-deployed HOBO loggers revealed strong changes in temperature accompanying tidal cycles and cycles of immersion/emersion (Fig. S3). The maximum temperature variation recorded in situ occurred during a low tide in the morning of 29 June, when the temperature swung from from $11.0^{\circ} \mathrm{C}$ at $6: 00 \mathrm{am}$ to a maximum of $33.7^{\circ} \mathrm{C}$ at $10: 08 a m$, then back to $13.3^{\circ} \mathrm{C}$ by $11: 00 \mathrm{am}$.

The impacts of desiccation under both high and low flow was examined by first placing 6 individuals onto plastic trays in sunlight for $1 \mathrm{~h}$. During this period, air temperature was $33.8^{\circ} \mathrm{C}$ (mean flow-through incubation temperature was $14.5^{\circ} \mathrm{C}$ ). After desiccation for $1 \mathrm{~h}$, individuals were placed into individual flow-through plastic boxes and monitored per the variable flow rate experiments described above. Comparison between desiccation and tissue homogenate challenge (described below) were performed against controls high/low flow as described above.

The effects of challenge with wasting tissue homogenates was examined in 4 individuals. A

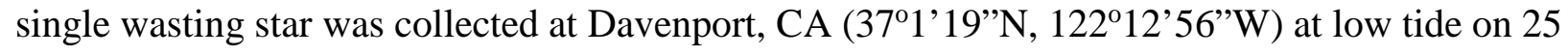
June 2018 and transported to the Long Marine Laboratory. Tissue surrounding lesions ( 2 g total) was excised using a sterile razor blade, and placed into $40 \mathrm{~mL}$ of seawater from the lab’s inflow system. The tissue was then homogenized in a sterilized mortar and pestle for $10 \mathrm{~min}$. Half of the tissue homogenate was treated with 10,000U of proteinase k (Sigma-Aldrich) and incubated for $1 \mathrm{~h}$ at $37^{\circ} \mathrm{C}$. Two Pisaster ochraceus were inoculated with $10 \mathrm{~mL}$ of crude tissue homogenate and two P. ochraceus inoculated with the proteinase-k treated homogenate by direct injection into their coelomic cavity. The inoculated asteroids were then placed in individual 
plastic flow-through aquaria (under low-flow conditions). Individuals were monitored per the flow-rate experiments described above.

Comparison of wasting time (lesion genesis) with experimental parameters: We modeled the time to wasting (i.e. lesion genesis time) across all experiments against available parameters, which varied between experiments (Table S2). All statistical analyses were performed using XLStat version 2019.4.1 in Microsoft Excel. Response of lesion time to treatment in OM addition experiments were examined by least squares mean ANOVA. The relationship between lesion time and comparison variables was performed by multiple linear regression, forward or backward selection procedure and change in Akaike’s AIC as entry criterion.

Association of wasting susceptibility with rugosity and surface area to volume ratio: We investigated whether inherent asteroid properties related to wasting susceptibility in context of BLODL by examining their rugosity (i.e. corrugated-ness), which is a key determinant of boundary layer extent. Individual, intact whole-animal specimens of asteroids were collected from several locations (Table S3) and immediately preserved in 20\% neutral buffered formalin. All individuals were transported to the lab at Cornell University. Computed tomography was performed on whole specimens at the Cornell University Equine Hospital without contrast to estimate surface area: volume using a Toshiba Aquillon computed tomographic multi-slice scanner.

The relative rugosity between wasting-affected and less wasting-affected asteroid species was examined by calculating the ratio of 3D (determined by computed tomography) to 2D (as calculated below) for each asteroid specimen and comparing between species. Asteroid species were categorized based on prevalence of wasting (less or not affected = Dermasterias imbricata, Henricia leviuscula, Patiria miniata; wasting affected = Pisaster ochraceus, Solaster stimpsoni, Pycnopodia helianthoides, Leptasterias sp., Asterias forbesi, Orthasterias kohleri, Pisaster giganteus and Pisaster brevispinus) as reported elsewhere (Montecino-Latorre et al., 2016;Bucci et al., 2017;Miner et al., 2018;Jaffe et al., 2019;Konar et al., 2019). These were likewise compared between animal volume, surface area:volume and 2D area.

Because the resolution of computed tomography is only $400 \mu \mathrm{m}$, which is larger than some surface features (e.g. papulae), we performed micro-CT ( $\mu \mathrm{CT}$ ) analyses on one large and one small individual of several key species after staining for at least $24 \mathrm{~h}$ in IKI solution (Fig. S4). X- 
Ray $\mu$ CT data were analyzed using the Avizo version 2019.4 software (ThermoFisher Scientific). Briefly, 2-D image slices were uploaded and stacked to reconstruct a 3-D volume for each specimen. A median filter was applied to each 3-D reconstruction to reduce noise and smooth edges. The volume of interest was isolated from surrounding background using a thresholding approach. Next, the total volume for each specimen was segmented into $1 \mathrm{~cm}$ sections (each composed of 500 stacked $20 \mu \mathrm{m}$ slices). After eliminating holes from each $1 \mathrm{~cm}$ sub-volume, the total volume, surface area, and rugosity were determined using the "Label Analysis” module of the Avizo software. The surface areas reported were calculated by subtracting the 2-D surface areas of the two, flat end slices from the total 3-D surface area for each 1-cm segment. The relationship between ray length and surface area was investigated by linear regression. We first calculated total two-dimensional area for each specimen by taking into consideration central disc radius and assuming triangular shape of rays, accounting for total height of central disc and height of ray tip (see Fig. S5). We then used the ratio of total surface area (determined by CT) to calculate surface area as a measure of rugosity. All image stacks for micro-CT analysis are available from MorphoSource (Duke University) under project accession P1047.

Asteroid Specimen Respiration: We hypothesized that specimens with greater respiratory $\mathrm{O}_{2}$ demand relative to their calculated $\mathrm{O}_{2}$ flux would be more susceptible to wasting. The respiration rates of individual asteroids was measured upon experiment initiation for Asterias forbesi and Pisaster ochraceus, and for additional species at the Bodega Marine Laboratory (Table S4). $\mathrm{HOBO} \mathrm{O}_{2}$ Loggers (U26; Onset) were placed into sealable plastic containers to which individuals were added. The incubations were circulated using a battery-operated submersible DC motor and propeller. The containers were then filled by immersion in flow-through seawater, and sealed, excluding all visible bubbles. Individuals were incubated for $1-2 \mathrm{hr}$ in containers

352 before retrieval of $\mathrm{O}_{2}$ probe. Respiration rate was calculated by the linear change in $\mathrm{O}_{2}$

353 concentration over time in incubations. Respiration rates were compared to calculated maximum

354 diffusion rates based on overall surface area determined by computed tomography using Fick’s 355 second law of diffusion $(\mathrm{J}=-\mathrm{D} * \partial \mathrm{C} / \partial \mathrm{d}$ where $\mathrm{J}=$ flux across the membrane, $\mathrm{D}=$ diffusivity 356 constant of $\mathrm{O}_{2}$ in seawater, $\mathrm{C}=$ concentration difference between coelomic fluid and seawater 357 in this case assuming completely anoxic coelomic fluid and saturated seawater, and $d=$ thickness 358 of outer epithelium -assumed to be $20 \mu \mathrm{m}$.) 
Time series analyses of wasting intensity and chlorophyll a at Whidbey Island: To understand the relationship between primary producer biomass (chlorophyll a), physico-chemical parameters (temperature, salinity, dissolved $\mathrm{O}_{2}$ ), and occurrence of wasting, we examined data obtained from the Penn Cove Shellfish data buoy and compared this to observations of wasting frequency at Coupeville Wharf and Langley Harbor as reported previously (Hewson et al., 2018) from August 2014 to June 2019 (i.e. 5 years). We also compared wasting frequency with precipitation data obtained from the National Center for Environmental Information (NOAA), which may be seen as a proxy for potential terrestrial runoff. We first calculated the mean time of wasting over the 5-year period and compared this to 5-year mean values of all parameters. We then performed at-time-of-wasting to prior to wasting comparison following a shifting window approach comparing the 3-month window immediately before wasting with 3-month windows in earlier months (Fig. S6).

Stable isotopic signatures in historical wasting asteroid specimens: The natural abundance of representing paired asymptomatic/wasting affected species at distinct sites and sampling times which were collected as part of prior work (Hewson et al., 2014) (Table S5). We included an additional 21 individuals of different species to provide context of stable isotopic composition. Samples were collected and frozen at $-20^{\circ} \mathrm{C}$ prior to analysis. Thawed tissue samples were subsectioned for analysis by scraping tube feet into sterile $1.2 \mathrm{ml}$ cryovials. Samples were freezedried at $-45^{\circ} \mathrm{C}$ for one week then ground with mortar and pestle. A subsample of $1 \mathrm{mg}$ of tissue was encapsulated into tin and subsequently analyzed on a Carlo Erba NC2500 Elemental Analyzer coupled to a Thermo Scientific Delta V Advantage IRMS (Bremen, Germany).

\section{RESULTS AND DISCUSSION}

The results of our work provide support for our hypothesis that sea star wasting is associated with the formation of anaerobic conditions adjacent to asteroid surfaces. First, we show that organic matter amendment leads to faster lesion genesis than untreated stars, which is preceded by increased bacterial abundance in some treatments and the proliferation of copiotrophic taxa on and above asteroid surfaces in all treatments. In asteroids which wasted in the absence of external stimuli, epidermal and body wall tissues showed a similar progression of copiotrophic 
bacterial orders, and at the time of lesion and until death the proliferation of strict and facultative anaerobes. Next, we show that lesions form as a consequence of exposure to suboxic water column conditions. We also demonstrate that wasting is correlated with primary production trends over 5 years at a field site. Finally, we provide further evidence of predominantly anaerobic conditions during mass mortality in $2013-2014$ by way of enriched ${ }^{15} \mathrm{~N}$ pools in affected tissues relative to asymptomatic individuals.

\section{Organic matter amendment stimulates boundary layer microorganisms and results in} rapid wasting

We sought to examine the impact of elevated heterotrophic bacterial respiration on animal surfaces through amendment with various sources of OM which we hypothesized would fuel microbial remineralization. We performed laboratory experiments in which $P$. ochraceus was amended with peptone, Dunaliella tertiolecta-derived particulate OM (POM), and coastal seawater POM and examined their impacts on SSW progression and boundary layer bacterial abundance and composition. The addition of organic substrates (peptone and Dunaliella tertiolecta-derived POM) induced significantly faster lesion genesis than control incubations

$404(\mathrm{p}=0.012$ for peptone and $\mathrm{p}=0.04$ for Dunaliella-POM, Student's t-test, $\mathrm{df}=5)$, but lesion genesis time was not significantly different for the addition of coastal-POM (Fig. 2). Collective treatment temporal pattern of lesion genesis was only significantly different from controls with amendment with peptone ( $\mathrm{p}=0.0154$, log-rank test, $\mathrm{df}=5)$ and Dunaliella-POM ( $\mathrm{p}=0.0339$, log-rank test, $\mathrm{df}=5$ ). Variation in dissolved $\mathrm{O}_{2}$ in incubations varied over the course of the experiment from 9.6 $-10.2 \mathrm{mg} \mathrm{L}^{-1}$ and were never under-saturated. Temperature varied from $12-14^{\circ} \mathrm{C}$, but variation did not correspond with wasting in any treatment.

412 experiment changed over time in all treatments (Figs. 3E-G; Figs S7), but the most prominent 413 changes were distinguished by the copiotrophic orders Flavobacteriales and Rhodobacterales 414 (Flavobacteriales; control: $\mathrm{p}<0.001$, Dunaliella: $\mathrm{p}=0.002$, peptone: $\mathrm{p}=0.001$, coastal POM: $\mathrm{p}$ $415<0.001$, ANOVA fit with a Generalized Linear Model) (Rhodobacteriales; control: $\mathrm{p}<0.001$, 416 Dunaliella: $\mathrm{p}<0.001$, peptone: $\mathrm{p}=0.010$, coastal POM: $\mathrm{p}<0.001$, ANOVA with a Generalized 417 Linear Model), which increased uniformly in all incubations, indicating that captivity alone may 418 stimulate these groups (i.e. containment affect; Fig. 4). We also observed evidence for treatment- 
specific proliferation of genera with OM enrichment. Unamended and peptone supplemented $P$. ochraceus experienced the most consistent change in Flavobacteriales, with both conditions exhibiting a linear increase in population mean relative to the mean of all other sub-OTUs. Flavobacteriales in coastal POM-supplemented P. ochraceus were elevated from the first to final timepoints, but were primarily distinguished by a large boom and bust after 96 h (c.f. bacterial abundance below). This spike was due to an increase in the family Crocinitomicaceae, which, in addition to the family Flavobacteriaceae, comprised the majority of Flavobacteriales across all treatments. Rhodobacterales, which primarily consisted of the family Rhodobacteraceae, increased in all experimental conditions.

Bacterial cell abundance on surfaces (relative to both initial values and controls) illustrated large swings prior to wasting onset (Fig. 5). Individuals that did not waste over the course of the experiment maintained abundances of $0.7-2.6 \times 10^{6}$ cells $\mathrm{mL}^{-1}$, which was enriched 53 to 1743\% above bacterioplankton abundances in incubation treatments (Fig. 5). On aggregate, wasting stars had higher bacterial abundances than non-wasting stars (Fig. S8), however the relationship was not significant because of high variation between treatments with OM.

Treatment bacterial abundances remained no different to controls over the first $48 \mathrm{~h}$ of incubation, but increased relative to controls in peptone and coastal-POM treated asteroids after 72 and 96 h, respectively. However, by $96 \mathrm{~h}$ for peptone and $120 \mathrm{~h}$ for coastal POM both amendments had again declined, and remained no different to controls after this time (Fig. 5). In contrast, bacterial abundance in Dunaliella-POM incubations were no different to controls over the first $48 \mathrm{~h}$ of incubation, and were far less than controls after $72 \mathrm{~h}$. Since bacterial abundance increased prior to lesion genesis in at least two OM treatments, we posit that wasting is influenced by copiotroph proliferation on animal surfaces. The decrease in bacterial abundance after initial increase in both peptone, coastal POM, and consistently lower bacterial abundance in Dunaliella-POM incubations may be evidence of heterotrophic remineralization-fueled $\mathrm{O}_{2}$ deficit over time on wasting asteroids, similar to the effect observed in our experiments with Asterias forbesi incubated in hypoxic water (see below). Facultative and strict anaerobes generally experience slow growth rates compared to aerobic taxa because it is less energetically efficient to grow on reduced electron acceptors. While standing stock of aquatic bacteria may be higher in anaerobic conditions than in aerobic conditions, population growth rates are typically lower (Cole and Pace, 1995). 
Shifts in heterotrophic bacterial and archaeal communities during wasting progression in the absence of external stimuli

Because sampling by biopsy punch imparts stress on animals that may elicit wasting, sampling in the absence of external stimuli focused on samples collected at the time of lesion genesis (August 2018) and samples collected after lesion genesis (May - June 2018), and are distinct from samples collected by surface swab (collected in organic matter enrichment experiment). Hence, compositional changes observed in these surveys likely reflect a combination of taxa that change prior to lesion formation and those that degrade tissues.

In the August 2018 study, Pisaster ochraceus developed lesions without stimuli beginning $5 \mathrm{~d}$ after isolation, and by $8 \mathrm{~d}$ more than half of incubated stars were symptomatic (Fig. 6). Lesions formed initially concomitant with an approx. $2^{\circ} \mathrm{C}$ swing in temperature, however continued in other stars as temperatures progressively decreased over the course of the experiment. Initial genesis of lesions was not accompanied by variation in either $\mathrm{DO}$ or $\mathrm{pH}$. Lesions were grossly characterized by nonfocal loss of epidermal tissues, which exposed underlying body wall tissues. Lesion margins were not remarkable in terms of coloration which would otherwise indicate melanization. Epidermal samples from these specimens revealed no significant difference in microbial composition between artificial and natural lesions in 3 specimens that wasted (PERMANOVA; P = 0.139; Fig. S9). Between initial samples and the time of lesion genesis, most taxa identified as differentially abundant were less abundant sub-OTUs. In the May-June 2018 study, we observed a progressive increase in copiotrophic orders between initial samples and those taken shortly after lesions had formed, including Campylobacterales $(\mathrm{p}<0.001)$,

472 Model) (Fig. 3A). This occurred concomitant with an increase in Nitrosopumilus and obligate 473 anaerobes (Deltaproteobacteria) relative to a large clade of typically fast-growing phyla (Alpha474 and Gammaproteobacteria) (Fig. 3B-D).

475 Following lesion formation, bacteria on surfaces likely experience a complex milieu of OM 476 molecules, including those from decaying tissues. We found evidence for the proliferation of 477 anaerobic taxa under these conditions by comparing microbial composition between lesion 478 formation and animal death. Between lesion genesis and animal death, we observed a further 479 increase in copiotrophs in body wall (May-June 2018) and epidermal (August 2018) samples, 
and a proliferation in microaerophiles (Arcobacter spp.), facultative anaerobes (Moritella spp.), and obligate anaerobic families (Clostridia, Fusobacteria and Bacteroidia) at time of death (Fig. 3A; Fig. S10). The two sub-OTUs with the largest F-statistic from regression over the entire course of wasting from initial samples to animal death belonged to the families Desulfobulbaceae $(\mathrm{p}<0.001)$ and Desulfovibrionacea $(\mathrm{p}=0.002$; ANOVA fit with a Generalized Linear Model). Both of these families are strictly anaerobic sulfate reducers. These results are consistent with the pattern of microbial assemblage variation observed in the organic matter amendment experiment. Previous study comparing wasting (specimens already had lesions) and asymptomatic asteroid-associated community gene transcription also noted the increase in transcripts from Propionibacterium, Lachnospiraceae and Methanosarcina, which are strict anaerobes, as well as Stigmatella and Staphylococcus, which are facultative anaerobes, as a proportion of total transcripts (Gudenkauf and Hewson, 2015).

\section{Microbial assemblage composition and abundance variation illustrates an increasingly anaerobic environment near asteroid surfaces}

Taken together, these studies suggest that lesion formation is associated with a general proliferation of bacteria, including well-known copiotrophic orders (including Flavobacteriaceae and Vibrio spp.) of marine bacteria. Several studies have observed the proliferation of copiotrophic taxa longitudinally during wasting, including genera within the families Flavobacteriaceae, Rhodobacteriacaea (Lloyd and Pespeni, 2018), Actinobacteria, and genera in the orders Altermonadales (Nunez-Pons et al., 2018), Vibrionales and Oceanospiralles (Hoj et al., 2018). These taxonomic groups are amongst the most active constituents of bacterioplankton and major players in marine OM degradation, some of which have facultative anaerobic metabolisms (Pinhassi et al., 2004;Choi et al., 2010;Buchan et al., 2014; Thiele et al., 2017;Pohlner et al., 2019). While it is tempting to ascribe pathogenicity traits to groups that are enriched on disease-affected tissues (based on members of the same family or genus causing pathology), or infer their role in community dysbiosis (i.e. the microbial boundary effect), this is not possible in the absence of demonstrated pathogenicity or strain-level assignment (Hewson, 2019). The observation of strict anaerobic bacteria in underlying tissues after lesions had formed suggest the creation of a depleted oxygen environment on asteroid surfaces in response to organic matter loading. 
All aquatic surfaces are coated with a thin film of water (i.e. diffusive boundary layer) that impedes gas and solute exchange, and, provided aerobic respiration is sufficiently high, suboxic conditions can form on a surface despite oxygen saturated water circulating above (Jørgensen and Revsbech, 1985). This may result in the proliferation of facultative and obligate anaerobes until asteroid death. Stimulation of bacteria and subsequent $\mathrm{O}_{2}$ diffusion limitation is well described in mammalian respiratory systems as well, and is especially pronounced in cystic fibrosis patients. Heterotrophic bacteria inhabiting mammalian lungs thrive on mucins and generate biofilms which further restrict $\mathrm{O}_{2}$ diffusion into tissues. $\mathrm{O}_{2}$ consumption by biofilms and by neutrophils may result in hypoxia and reduced diffusion of $\mathrm{O}_{2}$ across alveolar tissues $(\mathrm{Wu}$ et al., 2018). This in turn leads to the proliferation of anaerobes, which are present in clinically normal lungs (reviewed in Guilloux et al., 2018) and elevated in diseased lungs (Denner et al., 2016;Wang et al., 2019;Spence et al., 2020). This phenomenon is also observed in fish gills (Legrand et al., 2018;Meyer et al., 2019) which are inhabited by copiotrophic and potentially facultatively anaerobic taxa (Reverter et al., 2017;Rosado et al., 2019).

Rapid mineralization of dissolved OM by bacteria near asteroids has been noted previously in studies of epidermal amino acid uptake by Asterias rubrens, which ultimately led to decreased animal weight (Siebers, 1979), and may be responsible for very low ambient DOM concentrations adjacent to asteroids (Siebers, 2015). Remineralization of OM by heterotrophic microorganisms fuels oxygen consumption, which may in turn lead to oxygen deficit when consumption is not matched by gas diffusion. For example, excess phytoplankton-fueled bacterial respiration, caused by eutrophication and enrichment from terrestrial sources and upwelling zones may result in 'dead zones’ (e.g. Mississippi River Plume, Peruvian upwelling zone, Benguela current; reviewed in (Diaz and Rosenberg, 2008) and may be exacerbated by seasonal temperature changes (Murphy et al., 2011) and restricted bathymetry (Diaz, 2001). We posit that OM amendment stimulates bacterial abundance immediately adjacent to asteroid respiratory surfaces (i.e. within boundary layers) leading to suboxic microzones and ultimately limiting gas diffusion potential (Gregg et al., 2013).

Bacterial stimulation and enhanced wasting in asteroids is paralleled by the DDAM (dissolved organic carbon, disease, algae, microorganism) positive feedback loop in tropical corals (Dinsdale et al., 2008;Barott and Rohwer, 2012;Silveira et al., 2019). Coral disease is associated 
with OM enrichment (David et al., 2006;Smith et al., 2006), some of which originates from sympatric primary producers (Haas et al., 2010;Haas et al., 2011), which in turn are more labile than OM released from the corals themselves (Haas et al., 2016;Nakajima et al., 2018) and results in both elevated bacterial abundance on coral surfaces (Dinsdale and Rohwer, 2011;Haas et al., 2016), and enhanced remineralization rates (Haas et al., 2016). Bacteria at the coral-water interface have higher energetic demands than those in plankton (Roach et al., 2017), and are highly adapted to organic carbon availability in their local environment (Kelly et al., 2014). The spatial scale on which bacteria react to OM is primarily at water-surface interfaces (Brocke et al., 2015). Hypotheses for the mechanism of coral mortality caused by heterotrophic bacteria include disruption in the balance between corals and their associated microbiota (David et al., 2006), introduction of pathogens that have reservoirs on macroalgae (Nugues et al., 2004), or dysbiosis resulting in invasion by opportunistic pathogens (Barott and Rohwer, 2012). In black band disease, DOC released from primary production causes micro-zones of hypoxia which result in production of toxic sulfides, which in turn result in opening of niches for cyanobacteria (Sato et al., 2017). In asteroid wasting, the proliferation of heterotrophic bacteria and wasting disease may be due to any of these effects.

\section{Asteroid wasting is induced by suboxic conditions}

Our data demonstrate that SSW is induced by suboxic water column conditions. We incubated $A$. forbesi in suboxic water and observed patterns of wasting progression, boundary layer bacterial abundance and microbial assemblage $\beta$-diversity. Dissolved oxygen (DO) concentrations were controlled in an aquarium setting by continuous sparging with $\mathrm{N}_{2}$, which were on average $39 \%$ lower than untreated control incubations (Fig. 7). All individuals remained asymptomatic in control incubations over the 13 day experiment, while 75\% of individuals in hypoxic conditions developed lesions (mean time to lesion genesis $=9.58 \pm 0.89 \mathrm{~d}$; Fig. 7). Development of lesions over time was strongly related to treatment $(\mathrm{p}=0.006$, log-rank test, $\mathrm{df}=12)$. Bacterial abundance on animal surfaces (which we define as abundance in surface samples) corrected for aquarium water values increased in both control and suboxic treatments over the first 6d of incubation, but by day 13, abundance of bacteria in suboxic treatments was significantly lower ( $<<0.001$, Student's t-test, $\mathrm{df}=12$ ) on suboxic treated individuals than in control individuals (Fig. S11). Asterias forbesi treated with suboxic waters demonstrated consistent shifts in microbial 
communities with treatment (Fig. S9). However, no single bacterial taxonomic organization strongly differentiated normoxic from suboxic conditions.

Further evidence for the role of oxygen in SSW was observed in experiments comparing wasting speed under variable incubation flow rates (i.e. water replenishment rates). While we did nt measure DO concentrations in these experiments, higher flow rates likely had higher DO concentrations than lower flow rates, in addition to reducing OM (e.g. mucus) and toxic exudates in animal waste (notably $\mathrm{NH}_{3}$ [Propp et al., 1983] and $\mathrm{S}^{-}$[Vistisen and Vismann, 1997]). Furthermore, higher flow rates may have experienced less extensive boundary layers than lower flow rates (Fonseca and Kenworthy, 1987). The time to lesion genesis in Pisaster ochraceus was faster for asteroids under low-flow conditions than those under high flow conditions ( $\mathrm{p}=$ 0.006, Student's t-test, $\mathrm{df}=3$ ), however survival was not significantly different between flows (log-rank test, ns; Table S6). Desiccation, which was used to insult asteroids and simulate emersion during low tide events in warmer temperatures, resulted in faster lesion formation $(\mathrm{p}=$ 0.05, Student's t-test, $\mathrm{df}=3$ ) under low flow conditions, but not different under high flow conditions (log-rank test, ns; Fig. 8). Addition of tissue homogenates, which was initially used to assess transmissibility of tissue-derived agents, resulted in faster wasting than addition of proteinase $\mathrm{k}$ treated tissue homogenates ( $\mathrm{p}=0.04$, Student's t-test, $\mathrm{df}=3$ ); however, survival was no different between control treatment low flow and the addition of proteinase K-treated or untreated tissue homogenates (log rank test, ns; Fig. 8).

The mechanism by which asteroids are particularly sensitive to ambient $\mathrm{O}_{2}$ concentrations is not well constrained by empirical studies, especially as it relates to SSW. Asteroids mostly rely on passive respiration (c.f. ventilation) and gas diffusion across outer membranes to meet respiratory demand, a point illustrated by mass mortality events of benthic invertebrates, including asteroids, correlated to low $\mathrm{O}_{2}$ conditions (reviewed in Diaz and Rosenberg, 1995;Levin, 2003;Levin et al., 2009). Together, these data point to significant influence of $\mathrm{O}_{2}$ conditions on asteroid wasting. While water column hypoxia events were not observed in concert with SSW in 2013 and beyond, spatially localized hypoxia may occur near surfaces experiencing limited hydrodynamic flow (Gregg et al., 2013).

Analysis of covariance revealed that lesion time was explained best by different parameters, depending on the experiment. For Asterias forbesi, lesion genesis time variation was best 
600

601

602

603

604

605

606

607

608

609

610

611

612

613

614

615

616

617

618

619

620

621

622

623

624

625

626

627

628

629

explained by both overall animal mass change during the experiment and initial bacterial abundance ( $\mathrm{p}=0.12)$, while in Pisaster ochraceus experiments, both OM addition and combined with flow rate was best explained by initial animal mass $(p=0.006)$. In OM addition, variation in lesion genesis time was also explained by change in bacterial abundance over the first $3 \mathrm{~d}$ of incubation ( $p=0.018$ ) (Table S7). While these observations are entirely correlative - in other words, cannot reveal causality - they further indicate a key role of heterotrophic bacteria inhabiting the asteroid-seawater interface in wasting.

\section{Wasting is related to inherent asteroid properties that dictate boundary layer extent, gas diffusion, and respiration}

Inter- and intra-species susceptibility to asteroid wasting is extensively recorded in previous study, including a significant and positive relationship between individual size and wasting (Hewson et al., 2014), and shifts in size structure after wasting from larger to smaller individuals of Pisaster ochraceus, which was believed to be due to recruitment of juveniles (Bates et al., 2009;Eisenlord et al., 2016;Menge et al., 2016;Kay et al., 2019). Wasting in 2013-2014 affected $>20$ species of asteroid (Hewson et al., 2014), however the magnitude of SSW impact varied between species. Comparison of community structure before and after wasting suggests interspecies variability in wasting mortality. Asteriid taxa (Pycnopodia helianthoides, Pisaster spp., and Evasterias troschelii) experienced considerable declines in the Salish Sea (MontecinoLatorre et al., 2016;Schultz et al., 2016) and Southeast Alaska (Konar et al., 2019), while Dermasterias imbricata maintained or increased in abundance after mass mortality (Eckert et al., 1999;Montecino-Latorre et al., 2016;Schultz et al., 2016;Konar et al., 2019). In the Channel Islands, SSW disproportionately affected Asteriid taxa relative to D. imbricata and Patiria miniata (Eckert et al., 1999). Inter-species differences in wasting intensity have been noted in citizen science data accumulated by MARINe (Miner et al., 2018). The potential causes of interand within-species wasting susceptibility remain poorly constrained.

We hypothesized that wasting susceptibility may relate to both inter-species variation in rugosity (i.e. degree of corrugation), which dictates diffusive boundary layer thickness, and intra-species surface area-to-volume ratio, which determines total gas flux potential, which are ultimately reflected in patterns of population change since 2013 (Eckert et al., 1999;Montecino-Latorre et al., 2016). Mean and turbulent flow structure around aquatic animals and plants relates to the 
630

631

632

633

634

635

636

637

638

639

640

641

642

643

644

645

646

647

648

649

650

651

652

653

654

655

656

657

658

659

660

mean height, density and shape of structures as they compare to flat surfaces (Koch, 1994;Nepf, 2011;Brodersen et al., 2015). Asteroid surfaces bear numerous spines and processes, including papulae, spines, paxillae and pedicellaria. These structures impart rugosity and thus generate diffusive boundary layers proportional to their relative height under both mean and turbulent flow. For example, the boundary layer height above the urchin Evechinus chloroticus. can be 4-5 mm under low $\left(1.5 \mathrm{~cm} \mathrm{~s}^{-1}\right)$ flow conditions, which was approximately $2-6 \mathrm{X}$ greater than sympatric macroalgae (Hurd et al., 2011). We speculate that more extensive boundary layers may result in a greater deficit in $\mathrm{O}_{2}$ due to entrapment of $\mathrm{OM}$ adjacent to animal tissues, and also increase the potential for hypoxia at the animal surface since the effective distance over which $\mathrm{O}_{2}$ must diffuse is higher in specimens with greater boundary layer extent. Direct measurement of oxygen concentration in boundary layers as they relate to bacterial remineralization are precluded by the sensitivity of instruments (e.g. microelectrodes) to physical damage in nonimmobilized specimens.

To explore the relationship between species rugosity and wasting susceptibility, we examined specimens of similar size ( $\mathrm{n}=26$ individual specimens) representing wasting-affected $(\mathrm{n}=3)$ and less/not affected species $(n=5)$ using whole-animal computed tomography. CT-derived volume was significantly and positively correlated to overall mass across all specimens $(\mathrm{p}=$ $\left.0.00001, R^{2}=0.9999\right)$. To estimate overall surface area of specimens for which respirometry was measured (which were not imaged by CT), we modeled the surface area to ray length, and found it followed an exponential function (mean ray length $=0.0825 \mathrm{e}^{1.0536 * \mathrm{LOG}(\text { Surface area) }}, \mathrm{R}^{2}=0.93$. Log (Surface area) was significantly and linearly correlated to Log (Volume; LOG(Volume) = 0.7319*LOG(Surface Area) + 0.7662; R² = 0.9703); Fig. S20). The surface area: volume was significantly and negatively correlated with a logarithmic function defined as SA:Vol $=4.6242 \mathrm{e}^{-}$ 0.549[LOG(Volume)] (Fig. S12). The mean rugosity (defined as 3D:2D surface area) was significantly ( $p=0.015$, Student's t-test, $\mathrm{df}=14$ ) lower in less affected species than more affected species (Fig. 9). Surface area:volume, individual specimen mass, and overall surface area were not significantly different between categories among similarly-sized animals. Because analysis of large animal specimens is limited to a resolution of $400 \mu \mathrm{m}$ (which is potentially larger than finescale features, e.g. papulae on echinoderm surfaces), we performed further analysis on rays of a subset $(n=16)$ of individuals using micro-computed tomography, which has a resolution of 20 $\mu \mathrm{m}$. The rugosity of wasting-affected taxa was significantly $(\mathrm{p}=0.0002$, Student's t-test, $\mathrm{df}=4)$ 
661

662

663

664

665

666

667

668

669

670

671

672

673

674

675

676

677

678

679

680

681

682

683

684

685

686

687

688

689

690

greater than less-wasting affected species (Fig. 9). Our observation that more rugose species were more affected by wasting supports the idea that these individuals may be more susceptible because of their greater extent (physical distance) of diffusive boundary layers on respiratory surfaces.

Much of the intra-species wasting susceptibility may also be explained by inherent variation in diffusive flux potential. We observed a significant and positive relationship between wasting lesion genesis rate and initial animal mass $(\mathrm{p}=0.006$; analysis of covariance). Larger individuals have a much lower surface area:volume ratio, where surface area is related to gas flux potential. Under near-surface hypoxic conditions, or when diffusion is impeded by extensive boundary layers, larger individuals are more strongly affected than smaller individuals. We also posit that these observations are the result of more extensive boundary layer height above larger specimens. It is also important to note that ossicle density varies between species (Blowes et al., 2017), and those taxa with lower densities (e.g. Pycnopodia helianthoides) were more affected than those with higher densities (e.g. Pisaster ochraceus). Species with lower ossicle densities may be differentially susceptible to wasting since their structure may be broken down faster by microbial decomposition or apoptotic processes.

Wasting risk susceptibility may furthermore result from differential diffusive flux potential compared to respiratory demand. We measured the respiration rate (i.e. oxygen demand) of individuals at the start of each experiment, as well as in individuals of several species that were both affected by wasting and those that were less or not affected by wasting that were not a part of experiments to explore whether susceptibility was related to oxygen demand. Massnormalized measured respiration rates of asteroids were greatest for Asterias forbesi, and least for Dermasterias imbricata and Patiria miniata (Fig. S4). Both Pisaster ochraceus and Asterias forbesi respiration rates were considerably more than for other specimens. Measured respiration rates for entire animals was compared to theoretical maximum diffusion rates into coelomic fluids (hereafter abbreviated RR:TD). RR:TD was greatest in Asterias forbesi and Pisaster ochraceus (which were both $>1$ in most specimens) and least in Patiria miniata and Dermasterias imbricata (which were always < 0.1). The observed RR:TD corresponds with wasting susceptibility. Perturbation of $\mathrm{O}_{2}$ availability in animal surface boundary layers may skew diffusive flux by elongating diffusive path length or reducing differences in $\mathrm{O}_{2}$ between 
691

692

693

694

695

696

697

698

699

700

701

702

703

704

705

706

707

708

709

710

711

712

713

714

715

716

717

718

719

720

tissues and surrounding seawater. Hence, specimens with a higher RR:TD may be more affected by the condition than those with lower RR:TD. We cannot account for variable permeability of outer epidermis between individuals (not measured), and assume that all surface area of asteroids is involved in respiration (which may be over-estimated, since presumably some component of this area comprises mineral structures). Some asteroid species inhabiting typically suboxic environments employ morphological and behavioral strategies to meet $\mathrm{O}_{2}$ demand, including nidamental cavities (Johansen and Petersen, 1971;Nance, 1981), cribiform organs (Shick et al., 1981), epiproctoral cones (Shick, 1976), active ventilation of burrows and decreased size of internal organs (Mironov et al., 2016). However, it is unlikely asteroids typically occurring in normoxic intertidal or subtidal conditions have the ability to morphologically adapt to hypoxic conditions.

\section{Potential sources of OM fueling BLODL}

Heterotrophic bacteria in marine environments remineralize OM that originates from autochthonous and allochthonous sources (Ducklow, 1983;Benner et al., 1992;Amon and Benner, 1996). We hypothesize there are two primary sources fueling BLODL: OM from primary production (phytoplankton and macroalgae), and OM from decaying asteroids. Most asteroid wasting is reported in late fall or summer, with fewer reports during other times of the year (Eckert et al., 1999;Bates et al., 2009;Eisenlord et al., 2016;Menge et al., 2016;MontecinoLatorre et al., 2016;Hewson et al., 2018;Miner et al., 2018;Harvell et al., 2019;Hewson et al., 2019). Among the myriad of OM sources in seawater, phytoplankton-derived OM are highly labile (Ochiai et al., 1980;Ogawa and Tanoue, 2003;Thornton, 2014). We propose that wasting is associated with peak or post-peak declines in phytoplankton production in overlying waters, which subsequently results in peak dissolved OM availability. The mean time of wasting mass mortality observed at Langley and Coupeville, Whidbey Island between 2014 and 2019 fell at or within 1 month after the mean annual maximum of chlorophyll a, minimum DO concentration, maximum temperature, and minimum rainfall (Fig. 10). Multiple linear regression (stepwise, backwards selection criteria) revealed a significant model $\left(\mathrm{R}^{2}=0.866 ; \mathrm{p}=0.001\right)$ where temperature $(\mathrm{p}=0.006)$, chlorophyll a $(\mathrm{p}=0.027)$ and salinity $(\mathrm{p}=0.044)$ explained most variation in wasting mass mortality, while forward selection $\left(\mathrm{R}^{2}=0.774 ; \mathrm{p}=0.0002\right)$ revealed that monthly variation in wasting was significantly explained by DO alone. Mass mortality was 
721 significantly related (one-way ANOVA, $\mathrm{p}<0.0001$ ) to elevated chlorophyll in the previous 3

722 months relative to non-mass mortality months, to elevated salinity, and reduced rainfall (Fig.

723 S6). Because wasting occurs seasonally in late summer and early autumn, correlation between

724 these parameters alone does not necessarily indicate a direct link between primary production

725 and wasting. However, since we also observed that asteroids challenged with a phytoplankton

726 (Dunalella tertiolecta) formed lesions faster than unamended controls, it is entirely possible that

727 wasting is related to phytoplankton-derived DOM.

728 The coherence of wasting with primary production in the Salish Sea raises the question of why

729 wasting mass mortality in the northeast Pacific occurred in the 12 month period following June

730 2013, especially when asteroids normally persist at sites experiencing very high phytoplankton

731 biomass and only experienced wasting in 2014 (e.g. Cape Perpetua, OR; Leslie et al., 2005).

732 Suchy et al. (2019) observed a prolonged (10 month) period of decreased water column

733 stratification, concomitant with strong predominately southerly winds in fall 2013 and spring

7342014 in the northern Strait of Georgia. Chlorophyll a concentrations in the region was also higher

735 in the region in late 2013 compared to the previous 8 years (Suchy et al., 2019) and the 1981-

7362010 average (Moore et al., 2014) and was marked by a significant peak in late August (later

737 than previous years (Moore et al., 2014), concomitant with the lowest $\mathrm{NH}_{3}$ concentration

738 measured over several years at the Seattle Aquarium, presumably a consequence of

739 phytoplankton uptake (Olsen et al. 2016). Mean monthly precipitation was anomalously lower

740 in mid-summer compared to 2005-2012 means, but then increased dramatically in late

741 September 2013, prior to wasting onset in October (Hewson et al., 2018).

742 Elsewhere, there is evidence that wasting in 2013 - 2014 was tied to elevated primary

743 production. The high $\mathrm{pCO}_{2}$ but low temperature-wasting positive relationship noted in Oregon

744 indicates that upwelling may have stimulated primary production at this location (Menge et al.,

745 2016). The CALCoFi program observed highest coastal upwelling on record in 2013 in central

746 California during wasting onset (Leising et al., 2014). These observations suggest that primary

747 production intensity and timing in 2013-2014 departed from inter-annual variation in prior years,

748 and has followed seasonal patterns since 2014. The discontinuous latitudinal emergence of

749 wasting in 2013-2014 and regional apparent longshore sequence of SSW occurrence is consistent

750 with regional and basin-scale patterns of organic matter availability. The spatial scale of 
751 phytoplankton blooms sustained solely by terrestrial runoff and groundwater discharge ranges

752 from 880-3600 km² in the Southern California Bight (Santoro et al., 2010). Assuming these

753 blooms are constrained within $10 \mathrm{~km}$ of shore, the areal extent of phytoplankton-derived organic

754 matter inputs is well within the reported longshore spread of SSW (Hewson et al., 2014).

755 Upwelling, on the other hand, may affect wider coastal productivity patterns. In 2013, strong

756 upwelling was recorded between $36^{\circ} \mathrm{N}$ and $48^{\circ} \mathrm{N}$ (i.e. $1,332 \mathrm{~km}$ ). It is interesting to note that

757 mass mortality in Heliaster kubiniji in the Gulf of California occurred during a prolonged period

758 of heavy rainfall and elevated temperatures prior to El Niño (Dungan et al., 1982). Such rainfall

759 may have caused elevated terrestrial discharge, which in turn may have fueled primary

760 production.

761 Another potential source of organic matter fueling BLODL is macroalgal detritus (Krumhansl

762 and Scheibling, 2012) and exudates (Abdullah and Fredriksen, 2004). Macroalgae experience

763 seasonal increases in biomass during spring and fall due to elevated temperature and elevated

764 nutrient conditions, but may also experience nutrient limitation in summer (Brown et al., 1997).

765 For example, a study by (Van Alstyne, 2016) found that Ulva lactuca abundance was greatest in

766 July when compared to both May and September in Penn Cove. Interestingly the author found

767 that the primary source of nutrients for algal growth during the summer and fall was water from

768 a nearby river, as well as wastewater effluent from a facility at Coupeville (Van Alstyne, 2016).

769 Laminaria hyperborean in the North Atlantic Ocean has a pronounced seasonal productivity

770 cycle including an active growing season from February through May during which previous

771 year lamina are shed, followed by a non-growing season until November (Kain, 1979).

772 Exudation of dissolved OM is greatest during L. hyperborean's non-growing season (Abdullah

773 and Fredriksen, 2004). Both macroalgal detritus (Robinson et al., 1982) and exuded OM (Zhang

774 and Wang, 2017) are highly labile and rapidly assimilated by bacteria. While there have been no

775 studies of seasonal exudation or detrital release in the regions affected by SSW, the seasonal

776 variation of SSW and coherence with OM production and detrital breakdown (Krumhansl and

777 Scheibling, 2012) warrants further investigation.

778 OM originating from decaying asteroids may also generate BLODL. Experimental challenge 779 with asteroid tissue homogenates in this study (Fig. 8), and reported previously (Hewson et al., 780 2014;Bucci et al., 2017), suggest that wasting may also be associated with decomposition of 
nearby asteroid individuals via assimilation of tissue-derived compounds and subsequent BLODL. We previously isolated heterotrophic bacteria using sea star tissue homogenates as nutritional source (Hewson et al., 2018). These bacteria include well-known copiotrophic genera. Enrichment of near-benthic OM pools by wasting-affected individuals may have resulted in the apparent density dependence of wasting observed in 2014 in some populations (Hewson et al., 2014). Indeed, challenge with tissue homogenates by direct injection into coelomic cavities likely enriches within-and near animal organic matter pools, which in turn may stimulate heterotrophic remineralization. Hence, challenge experiments, such as those performed previously (Hewson et al., 2014;Bucci et al., 2017) and in this study, may be a consequence of BLODL induced by organic matter availability (and possibly protein-bearing material). The apparent transmissibility of SSW in field sites is based on observations of density dependence at some sites, along with geographic spread between adjacent sites and through public aquaria intake pipes (Hewson et al. 2014). These observations may be inaccurately ascribed to transmissible pathogenic microorganisms, since they may also be explained by enrichment of surrounding habitats and through intake pipes of organic matter pools from decaying individuals.

\section{Wasted asteroids in 2013-2017 bore stable isotopic signatures of anaerobic processes}

Because wasting has no pathognomic signs and has been reported for over a century (reviewed in Hewson et al., 2019), an obvious question is whether BLODL was related to asteroid mass mortality observed from 2013. While retrospective analyses of $\mathrm{O}_{2}$ status of asteroids during this event is not possible, hypoxic conditions impart elemental signatures in tissues of preserved specimens. We examined the natural abundance of stable isotopes comparing wasting-affected and grossly normal individuals at the same location and time, in 2013 and 2014. The natural abundance of $15 \mathrm{~N}\left(\delta^{15} \mathrm{~N}\right)$ and $\delta^{13} \mathrm{C}$ varied between species, with highest values for Hippasteria spinosa and lowest for Pteraster tesselatus (Fig. S13). There was no correspondence between known diet of asteroids (and, hence, food web position) and relative stable isotope composition between species. The elemental composition of asteroids, like all animals, largely reflects nutritional source, who obtain anabolic material from consumed prey. Furthermore, asteroids may take up DOM directly from the water column and use these materials for soft body parts, like tube feet (Ferguson, 1967b;a). The half-life of isotopic signatures in tissues relates to tissue 
811 turnover and is most stable in ectotherms (Vander Zanden et al., 2015). Dissimilatory anaerobic

812 nitrogen cycling processes, such as denitrification, shift the balance between ${ }^{15} \mathrm{~N}$ and ${ }^{14} \mathrm{~N}$ (i.e. selecting against ${ }^{15} \mathrm{~N}$ ), resulting in higher $\delta^{15} \mathrm{~N}$ (ratio of tissue ${ }^{15} \mathrm{~N}$ to atmospheric ${ }^{15} \mathrm{~N}$ ) in

814 environments. Thus, we restricted our analysis of tissue $\delta^{15} \mathrm{~N}$ to fast-growing, regenerative tube

815 feet which will therefore reflect the most recent environmental conditions prior to collection.

816 Wasting asteroids (including Pisaster ochraceus, Pycnopodia helianthoides, and Evasterias

817 troschelii), had generally higher $\delta^{15} \mathrm{~N}$ in their tissues than asymptomatic tissues at the same site

818 within-species (ns) except for Leptasterias sp., which had significantly lower $\delta^{15} \mathrm{~N}$ in wasting

819 tissues than in asymptomatic individuals (Fig. 11). On average, $\delta^{15} \mathrm{~N}$ was enriched by $3.9 \pm 3.3$

$820 \%$ for each species (7.0 $\pm 2.8 \%$ excluding Leptasterias sp.) in wasted compared to asymptomatic

821 stars. Ellipse analysis, which can be used to infer isotopic niches or metabolic differences

822 between populations (Jackson et al., 2011) suggested that in all paired site-species comparisons

823 wasted stars have altered $\mathrm{C}$ and $\mathrm{N}$ metabolisms compared to asymptomatic individuals (Fig.

824 S14).

825 Translocation of consumed elements to growing tissues is accomplished through continual flux 826 from digestive glands to these tissues through coelomic fluid (Ferguson, 1964). Internal tissues

827 of asteroids are inhabited by a suite of bacteria and archaea (Jackson et al., 2018) including 828 abundant spirochaetes (Holland and Nealson, 1978;Kelly et al., 1995;Kelly and McKenzie, 829 1995; Nakagawa et al., 2017). Hence, asteroid tube feet tissues, which are distal from digestive glands, may be influenced by heterotrophic microbial activities which enrich for ${ }^{15} \mathrm{~N}$ over ${ }^{14} \mathrm{~N}$.

831 Our finding of higher $\delta^{15} \mathrm{~N}$ in most wasted asteroids supports the hypothesis that wasting is 832 associated with enhanced anaerobic dissimilatory respiration of nitrogen species, perhaps during 833 translocation of materials between organs or tissues within asteroids, (Ferguson, 1964) or during uptake of enriched ${ }^{15} \mathrm{~N}$ in DOM pools surrounding affected asteroids (Ferguson, 1967b;a).

835 To the best of our knowledge, there has only been one previous report on the effects of hypoxia 836 on stable isotopic composition in animal tissues. Oysters affected by hypoxic water conditions 837 demonstrated $\delta^{15} \mathrm{~N}$ enrichment, which they propose was due to hypoxia-induced starvation 838 responses resulting in recycling of internal tissues (Patterson and Carmichael, 2018). Asteroids 839 likewise have similar autophagous responses to starvation, prioritizing somatic maintenance over reproduction (AQUINAS and P., 1976;Harrold and Pearse, 1980). Under typical food 
841 availability, reproductive and digestive tissues demonstrate inverse relationships in overall size

842 relating to spawning and feeding time in most asteroid species. However, the ratio between

843 reproductive and digestive tissues in Leptasterias spp. is synchronous over time in females (but

844 not so in males), which is different from other starfish species (Menge, 1975). We speculate that

845 the lower $\delta^{15} \mathrm{~N}$ observed in wasting Leptasterias spp., an opposite trend to other species, may

846 relate to timing of autophagous transfer of materials within individuals and timing of predicted

847 hypoxia (which peaks in late summer) relative to autophagy within animals. It is also possible

848 that asymptomatic and wasting affected specimens were different species of Leptasterias sp.

849 since they form a cryptic species complex (Melroy et al., 2017), which may affect comparison

850 between disease states.

851 Further evidence for BLODL association with wasting

852 Wasting imparts transcriptional and population genetic changes in asteroids and surviving 853 populations, respectively. In a metatranscriptomic studies comparing gene expression between 854 wasting and asymptomatic individuals, the relative transcription of high affinity cytochrome c 855 oxidase (ccb3; Preisig et al., 1996) was higher in symptomatic individuals (Gudenkauf and 856 Hewson, 2015). Furthermore, cytochrome P450 2J6, which plays a dual role in both oxidation 857 and detoxification of $\mathrm{H}_{2} \mathrm{~S}$ (Tobler et al., 2014), was expressed in at least two studies of wasting 858 asteroids (Fuess et al., 2015;Gudenkauf and Hewson, 2015). Surviving juvenile recruits are 859 genetically distinct to asteroids before 2013 (Schiebelhut et al., 2018). Loci selected for in 860 surviving populations correspond to those heightened in experiments with elevated temperature 861 (Ruiz-Ramos et al., 2020). In particular, Ruiz-Ramos et al (2020) found a synchronous decrease 862 in expression of ND5 (NADH dehydrogenase 5) among field-wasting specimens and those 863 subject to temperature challenge in aquaria, and corresponding mutation in ND5 in surviving 864 populations. Extracellular hypoxia causes downregulation of NADH dehydrogenase in vertebrate 865 cells (Piruat and López-Barneo, 2005), and variation in mt ND5 genes is related to hypoxia 866 sensitivity in humans (Sharma et al., 2019). Elevated temperatures may reduce overall $\mathrm{O}_{2}$ 867 concentrations in seawater and cause faster microbial growth rates. Hence, previous observations 868 of enhanced temperature corresponding to wasting (Eisenlord et al., 2016;Kohl et al., 869 2016;Montecino-Latorre et al., 2016;Miner et al., 2018;Harvell et al., 2019) and with periodic 
870

871

872

873

874

875

876

877

878

879

880

881

882

883

temperature excursion frequency (Aalto et al., 2020) are consistent with the BLODL model proposed in our work.

\section{Conclusion}

Here we present evidence to support our hypothesis that wasting is a sequela of BLODL. We provide evidence that this condition may relate to bacterial abundance/compositional shifts on asteroid respiratory surfaces, and that this results from enrichment with OM. While we cannot definitiely identify a specific source of OM that may lead to BLODL, inter-annual wasting in the field corresponds with phytoplankton biomass, and in controlled experiments we demonstrate that algal-derived OM stimulates wasting. We also provide evidence for this effect as occurring in specimens from the 2013 - 2014 mass mortality event. BLODL may be exacerbated under warmer ocean conditions, or conditions in which labile OM from terrestrial sources (which may include anthropogenic nutrient pollution) may be present in coastal environments. Holothurian wasting, bearing similarity to asteroid wasting in gross disease signs, was reported in the Puget Sound and southeast Alaska beginning in 2014 concomitant with asteroid mass mortality (Hewson et al., 2020) suggesting that this phenomena may affect sympatric benthic invertebrates. Most urchin diseases are associated with diverse bacteria capable of anaerobic metabolism (reviewed in Hewson, 2019). Hence, BLODL may help explain the variation in etiologies observed between echinoderms and between other invertebrate groups, especially those that rely on diffusion for respiratory activities.

\section{ACKNOWLEDGEMENTS}

The authors are grateful to Jim Nagel (Penn Cove Shellfish Company), Karl Menard (Bodega Bay Marine Laboratory), Taylor White (UC Santa Cruz), Joe Gaydos, Lizzy Ashley (Seadoc Society), Martin Haulena (Vancouver Aquarium), Lesanna Lahner (Minnesota Zoo) and Kipp

Quinby for provision of specimens and data; Betsy Steele (UC Santa Cruz), Joel Markis and Marnie Chapman (University of Alaska Southeast) for use of laboratory space; Kim Sparks and Elliot Jackson (Cornell University) for laboratory assistance; Mary Sewell (U Auckland), Christopher Mah (Smithsonian); Tom Mumford (University of Washington) for helpful 
conversations on macroalgae; and Thierry Work (USGS) for assistance with experiments and comments on an early manuscript draft. Asteroid collections were performed under permits CF19-107 from the Alaska Department of Fish and Game, 19-149a from the Washington State Department of Fish and Wildlife and SC-13144 from the California Department of Fish and Wildlife. This manuscript has been released as a pre-print at biorxiv (Aquino et al., 2020). This work was supported by US National Science Foundation Grants OCE-1537111 and OCE1737127 awarded to IH and USGS Contract G19AC00434 awarded to IH and T. Work. The authors declare no conflict of interest in publication of this work.

Author Contributions: LMS and IH designed research; CA, RMB, CMD, JK, IRP, PR, JER, LMS, JPS and IH performed research; CA, RMB, CMD, IRP, PR, JER, LMS, JPS, JPW and IH conducted review and wrote the manuscript; PR and IH provided funding for the research.

\section{References}

Aalto, E.A., Lafferty, K.D., Sokolow, S.H., Grewelle, R.E., Ben-Horin, T., Boch, C.A., Raimondi, P.T., Bograd, S.J., Hazen, E.L., Jacox, M.G., Micheli, F., and De Leo, G.A. (2020). Models with environmental drivers offer a plausible mechanism for the rapid spread of infectious disease outbreaks in marine organisms. Sci Rep 10, 5975.

Abdullah, M.I., and Fredriksen, S. (2004). Production, respiration and exudation of dissolved organic matter by the kelp Laminaria hyperborea along the west coast of Norway. $J$ Mar Biol Assoc UK 84, 887-894.

Amir, A., Mcdonald, D., Navas-Molina, J.A., Kopylova, E., Morton, J.T., Zech Xu, Z., Kightley, E.P., Thompson, L.R., Hyde, E.R., Gonzalez, A., and Knight, R. (2017). Deblur Rapidly Resolves Single-Nucleotide Community Sequence Patterns. mSystems 2, e00191-00116.

Amon, R.M.W., and Benner, R. (1996). Bacterial utilization of different size classes of dissolved organic matter. Limnol Oceanogr 41, 41-51.

Aquinas, S.M., and P., N.O. (1976). Histochemical changes in gonadal nutrient reserves correlated with nutrition in the sea stars, Pisaster ochraceus and Patiria miniata. Biol Bull 151, 357-369.

Aquino, C.A., Besemer, R.M., Derito, C.M., Kocian, J., Porter, I.R., Raimondi, P.T., Rede, J.E., Schiebelhut, L.M., Sparks, J.P., Wares, J.P., and Hewson, I. (2020). Evidence for 
boundary layer oxygen diffusion limitation as a key driver of asteroid wasting. bioRxiv, doi: https://doi.org/10.1101/2020.1107.1131.231365

Barott, K.L., and Rohwer, F.L. (2012). Unseen players shape benthic competition on coral reefs. Trend Microbiol 20, 621-628.

Bates, A.E., Hilton, B.J., and Harley, C.D.G. (2009). Effects of temperature, season and locality on wasting disease in the keystone predatory sea star Pisaster ochraceus. Dis Aquat Org 86, 245-251.

Benner, R., Pakulski, J.D., Mccarthy, M., Hedges, J.I., and Hatcher, P.G. (1992). Bulk chemical characteristics of dissolved organic matter in the ocean. Science 255, 1561-1564.

Blowes, L.M., Egertová, M., Liu, Y., Davis, G.R., Terrill, N.J., Gupta, H.S., and Elphick, M.R. (2017). Body wall structure in the starfish Asterias rubens. J Anatom 231, 325-341.

Brocke, H.J., Polerecky, L., De Beer, D., Weber, M., Claudet, J., and Nugues, M.M. (2015). Organic matter degradation drives benthic cyanobacterial mat abundance on Caribbean coral reefs. PLoS One 10, e0125445.

Brodersen, K., Lichtenberg, M., Paz, L.-C., and Kühl, M. (2015). Epiphyte-cover on seagrass (Zostera marina L.) leaves impedes plant performance and radial $\mathrm{O}_{2}$ loss from the belowground tissue. Front Mar Sci 2.

Brown, M.T., Nyman, M.A., Keogh, J.A., and Chin, N.K.M. (1997). Seasonal growth of the giant kelp Macrocystis pyrifera in New Zealand. Mar Biol 129, 417-424.

Bucci, C., Francoeur, M., Mcgreal, J., Smolowitz, R., Zazueta-Novoa, V., Wessel, G.M., and Gomez-Chiarri, M. (2017). Sea Star Wasting Disease in Asterias forbesi along the Atlantic Coast of North America. PLoS One 12, 20.

Buchan, A., Lecleir, G.R., Gulvik, C.A., and González, J.M. (2014). Master recyclers: features and functions of bacteria associated with phytoplankton blooms. Nat Rev Microbiol 12, 686-698.

Caporaso, J.G., Kuczynski, J., Stombaugh, J., Bittinger, K., Bushman, F.D., Costello, E.K., Fierer, N., Peña, A.G., Goodrich, J.K., Gordon, J.I., Huttley, G.A., Kelley, S.T., Knights, D., Koenig, J.E., Ley, R.E., Lozupone, C.A., Mcdonald, D., Muegge, B.D., Pirrung, M., Reeder, J., Sevinsky, J.R., Turnbaugh, P.J., Walters, W.A., Widmann, J., Yatsunenko, T., Zaneveld, J., and Knight, R. (2010). QIIME allows analysis of high-throughput community sequencing data. Nat Method 7, 335-336. 
Caporaso, J.G., Lauber, C.L., Walters, W.A., Berg-Lyons, D., Lozupone, C.A., Turnbaugh, P.J., Fierer, N., and Knight, R. (2011). Global patterns of 16S rRNA diversity at a depth of millions of sequences per sample. Proc Nat Acad Sci USA 108, 4516-4522.

Choi, E.J., Kwon, H.C., Sohn, Y.C., and Yang, H.O. (2010). Kistimonas asteriae gen. nov., sp. nov., a gammaproteobacterium isolated from Asterias amurensis. Internat J System Evol Microbiol 60, 938-943.

Cole, J.J., and Pace, M.L. (1995). Bacterial secondary production in oxic and anoxic freshwaters. Limnol Oceanogr 40, 1019-1027.

David, I.K., Neilan, M.K., Mya, B., Nancy, K., and Forest, R. (2006). Role of elevated organic carbon levels and microbial activity in coral mortality. Mar Ecol Progr Ser 314, 119-125.

Denner, D.R., Sangwan, N., Becker, J.B., Hogarth, D.K., Oldham, J., Castillo, J., Sperling, A.I., Solway, J., Naureckas, E.T., Gilbert, J.A., and White, S.R. (2016). Corticosteroid therapy and airflow obstruction influence the bronchial microbiome, which is distinct from that of bronchoalveolar lavage in asthmatic airways. J Allerg Clin Immunol 137, 1398-+.

Diaz, R.J. (2001). Overview of hypoxia around the world. J Environ Qual 30, 275-281.

Diaz, R.J., and Rosenberg, R. (1995). Marine benthic hypoxia: A review of its ecological effects and the behavioural responses of benthic macrofauna. Oceanogr Mar Biol Ann Rev 33, 245-303.

Diaz, R.J., and Rosenberg, R. (2008). Spreading dead zones and consequences for marine ecosystems. Science 321, 926-929.

Dinsdale, E.A., Pantos, O., Smriga, S., Edwards, R.A., Angly, F., Wegley, L., Hatay, M., Hall, D., Brown, E., Haynes, M., Krause, L., Sala, E., Sandin, S.A., Thurber, R.V., Willis, B.L., Azam, F., Knowlton, N., and Rohwer, F. (2008). Microbial ecology of four coral atolls in the northern Line Islands. PLoS One 3, e1584.

Dinsdale, E.A., and Rohwer, F. (2011). "Fish or germs? Microbial dynamics associated with changing trophic structures on Coral Reefs," in Coral Reefs: An Ecosystem in Transition, eds. Z. Dubinsky \& N. Stambler. (Dordrecht: Springer Netherlands), 231-240.

Ducklow, H.W. (1983). Production and fate of bacteria in the oceans. Bioscience 33, 494-501. Dungan, M.L., Miller, T.E., and Thomson, D.A. (1982). Catastrophic decline of a top carnivore in the Gulf of California rocky intertidal zone. Science 216, 989-991. 
Eckert, G., Engle, J.M., and Kushner, D. (Year). "Sea star disease and population declines at the Channel Islands", in: Proceedings of the 6th California Islands Symposium, 435-441.

Eisenlord, M.E., Groner, M.L., Yoshioka, R.M., Elliott, J., Maynard, J., Fradkin, S., Turner, M., Pyne, K., Rivlin, N., Van Hooidonk, R., and Harvell, C.D. (2016). Ochre star mortality during the 2014 wasting disease epizootic: role of population size structure and temperature. Phil Transac Roy Soc B 371, 20150212.

Ferguson, J.C. (1964). Nutrient transport in starfish. I. Properties of the coelomic fluid. Biol Bull 126, 33-53.

Ferguson, J.C. (1967a). An autoradiographic study of the utilization of free exogenous amino acids by starfishes. Biol Bull 133, 317-329.

Ferguson, J.C. (1967b). Utilization of dissolved exogenous nutrients by the starfishes, Asterias forbesi and Henricia sanguinolenta. Biol Bull 132, 161-173.

Fonseca, M.S., and Kenworthy, W.J. (1987). Effects of current on photosynthesis and distribution of seagrasses. Aquat Bot 27, 59-78.

Friedman, J., Hastie, T., and Tibshirani, R. (2010). Regularization paths for generalized linear models via coordinate descent. J Statistic Software 33, 1-22.

Fuess, L.E., Eisenlord, M.E., Closek, C.J., Tracy, A.M., Mauntz, R., Gignoux-Wolfsohn, S., Moritsch, M.M., Yoshioka, R., Burge, C.A., Harvell, C.D., Friedman, C.S., Hewson, I., Hershberger, P.K., and Roberts, S.B. (2015). Up in arms: Immune and nervous system response to sea star wasting disease. PLoS One 10, e0133053.

Gonzalez, A., Navas-Molina, J.A., Kosciolek, T., Mcdonald, D., Vázquez-Baeza, Y., Ackermann, G., Dereus, J., Janssen, S., Swafford, A.D., Orchanian, S.B., Sanders, J.G., Shorenstein, J., Holste, H., Petrus, S., Robbins-Pianka, A., Brislawn, C.J., Wang, M., Rideout, J.R., Bolyen, E., Dillon, M., Caporaso, J.G., Dorrestein, P.C., and Knight, R. (2018). Qiita: rapid, web-enabled microbiome meta-analysis. Nat Method 15, 796-798.

Gregg, A.K., Hatay, M., Haas, A.F., Robinett, N.L., Barott, K., Vermeij, M.J.A., Marhaver, K.L., Meirelles, P., Thompson, F., and Rohwer, F. (2013). Biological oxygen demand optode analysis of coral reef-associated microbial communities exposed to algal exudates. PeerJ 1, e107.

Gudenkauf, B.M., and Hewson, I. (2015). Metatranscriptomic analysis of Pycnopodia helianthoides (Asteroidea) affected by sea star wasting disease. PLoS One 10, e0128150. 
Guilloux, C.A., Lamoureux, C., and Hery-Arnaud, G. (2018). Anaerobic bacteria, the unknown members of the lung microbiota. M S-Medecine Sciences 34, 253-260.

Haas, A.F., Fairoz, M.F.M., Kelly, L.W., Nelson, C.E., Dinsdale, E.A., Edwards, R.A., Giles, S., Hatay, M., Hisakawa, N., Knowles, B., Lim, Y.W., Maughan, H., Pantos, O., Roach, T.N.F., Sanchez, S.E., Silveira, C.B., Sandin, S., Smith, J.E., and Rohwer, F. (2016). Global microbialization of coral reefs. Nat Microbiol 1, 16042.

Haas, A.F., Naumann, M.S., Struck, U., Mayr, C., El-Zibdah, M., and Wild, C. (2010). Organic matter release by coral reef associated benthic algae in the Northern Red Sea. J Exper Mar Biol Ecol 389, 53-60.

Haas, A.F., Nelson, C.E., Wegley Kelly, L., Carlson, C.A., Rohwer, F., Leichter, J.J., Wyatt, A., and Smith, J.E. (2011). Effects of coral reef benthic primary producers on dissolved organic carbon and microbial activity. PloS One 6, e27973-e27973.

Harrold, C., and Pearse, J.S. (1980). Allocation of pyloric caecum reserves in FED and starved sea stars, Pisaster giganteus (Stimpson): somatic maintenance comes before reproduction. J Exper Mar Biol Ecol 48, 169-183.

Harvell, C.D., Montecino-Latorre, D., Caldwell, J.M., Burt, J.M., Bosley, K., Keller, A., Heron, S.F., Salomon, A.K., Lee, L., Pontier, O., Pattengill-Semmens, C., and Gaydos, J.K. (2019). Disease epidemic and a marine heat wave are associated with the continentalscale collapse of a pivotal predator (Pycnopodia helianthoides). Sci Advan 5, eaau7042.

Hewson, I. (2019). Technical pitfalls that bias comparative microbial community analyses of aquatic disease. Dis Aquat Organ 137, 109-124.

Hewson, I., Bistolas, K.S.I., Carde, E.M.Q., Button, J.B., Foster, P.J., Flanzenbaum, J.M., Kocian, J., and Lewis, C.K. (2018). Investigating the complex association between viral ecology, environment, and Northeast Pacific sea star wasting. Front Mar Sci 5. https://doi.org/10.3389/fmars.2018.00077.

Hewson, I., Button, J.B., Gudenkauf, B.M., Miner, B., Newton, A.L., Gaydos, J.K., Wynne, J., Groves, C.J., Hendler, G., Murray, M., Fradkin, S., Breitbart, M., Fahsbender, E., Lafferty, K.D., Kilpatrick, A.M., Miner, C.M., Raimondi, P., Lahner, L., Friedman, C.S., Daniels, S., Haulena, M., Marliave, J., Burge, C.A., Eisenlord, M.E., and Harvell, C.D. (2014). Densovirus associated with sea-star wasting disease and mass mortality. Proc Nat Acad Sci USA 111, 17276-17283. 
1052

1053

1054

1055

1056

1057

1058

1059

1060

1061

1062

1063

1064

1065

1066

1067

1068

1069

1070

1071

1072

1073

1074

1075

1076

1077

1078

1079

1080

1081

Hewson, I., Johnson, M.R., and Tibbetts, I.R. (2020). An unconventional flavivirus and other RNA viruses in the sea cucumber (Holothuroidea; Echinodermata) virome. Viruses 12, 1057.

Hewson, I., Sullivan, B., Jackson, E.W., Xu, Q., Long, H., Lin, C., Quijano Cardé, E.M., Seymour, J., Siboni, N., Jones, M.R.L., and Sewell, M.A. (2019a). Perspective: Something old, something new? Review of wasting and other mortality in Asteroidea (Echinodermata). Front Mar Sci 6.

Hoj, L., Levy, N., Baillie, B.K., Clode, P.L., Strohmaier, R.C., Siboni, N., Webster, N.S., Uthicke, S., and Bourne, D.G. (2018). Crown-of-Thorns sea star Acanthaster cf. solaris has tissue characteristic microbiomes with potential roles in health and reproduction. Appl Environ Microbiol 84.

Holland, N.D., and Nealson, K.H. (1978). Fine-structure of the echinoderm cuticle and the subcuticular bacteria of echinoderms. Acta Zool 59, 169-185.

Hurd, C.L., Cornwall, C.E., Currie, K., Hepburn, C.D., Mcgraw, C.M., Hunter, K.A., and Boyd, P.W. (2011). Metabolically induced $\mathrm{pH}$ fluctuations by some coastal calcifiers exceed projected 22nd century ocean acidification: a mechanism for differential susceptibility? Global Change Biology 17, 3254-3262.

Jackson, A.L., Inger, R., Parnell, A.C., and Bearhop, S. (2011). Comparing isotopic niche widths among and within communities: SIBER - Stable Isotope Bayesian Ellipses in R. J Anim Ecol 80, 595-602.

Jackson, E.W., Pepe-Ranney, C., Debenport, S.J., Buckley, D.H., and Hewson, I. (2018). The microbial landscape of sea stars and the anatomical and interspecies variability of their microbiome. Front Microbiol 9, 12.

Jackson, E.W., Pepe-Ranney, C., Johnson, M.R., Distel, D.L., and Hewson, I. (2020a). A highly prevalent and pervasive densovirus discovered among sea stars from the North American Atlantic coast. Appl Environ Microbiol 86.

Jackson, E.W., Wilhelm, R.C., Johnson, M.R., Lutz, H.L., Danforth, I., Gaydos, J.K., Hart, M.W., and Hewson, I. (2020b). Diversity of sea star-associated densoviruses and transcribed endogenized viral elements of densovirus origin. bioRxiv, 2020.2008.2005.239004. 
Jaffe, N., Eberl, R., Bucholz, J., and Cohen, C.S. (2019). Sea star wasting disease demography and etiology in the brooding sea star Leptasterias spp. PloS One 14, e0225248-e0225248.

Johansen, K., and Petersen, J.A. (1971). Gas exchange and active ventilation in a starfish, Pteraster tesselatus. Zeitschrift für vergleichende Physiologie 71, 365-381.

Jørgensen, B.B., and Revsbech, N.P. (1985). Diffusive boundary layers and the oxygen uptake of sediments and detritus. Limnol Oceanogr 30, 111-122.

Kain, J. (1979). A view of the genus Laminaria. Oceanogr Mar Biol Ann Rev 17, 101-161.

Kay, S.W.C., Gehman, A.-L.M., and Harley, C.D.G. (2019). Reciprocal abundance shifts of the intertidal sea stars, Evasterias troschelii and Pisaster ochraceus, following sea star wasting disease. Proc Roy Soc B 286, 20182766.

Kelly, L.W., Williams, G.J., Barott, K.L., Carlson, C.A., Dinsdale, E.A., Edwards, R.A., Haas, A.F., Haynes, M., Lim, Y.W., Mcdole, T., Nelson, C.E., Sala, E., Sandin, S.A., Smith, J.E., Vermeij, M.J.A., Youle, M., and Rohwer, F. (2014). Local genomic adaptation of coral reef-associated microbiomes to gradients of natural variability and anthropogenic stressors. Proc Nat Acad Sci USA 111, 10227-10232.

Kelly, M.S., Barker, M.F., Mckenzie, J.D., and Powell, J. (1995). The incidence and morphology of subcuticular bacteria in the echinoderm fauna of New Zealand. Biol Bull 189, 91-105.

Kelly, M.S., and Mckenzie, J.D. (1995). Survey of the occurrence and morphology of subcuticular bacteria in shelf echinoderms from the north-east Atlantic Ocean. Mar Biol 123, 741-756.

Koch, E.W. (1994). Hydrodynamics, diffusion-boundary layers and photosynthesis of the seagrasses Thalassia testudinum and Cymodocea nodosa. Mar Biol 118, 767-776.

Kohl, W.T., Mcclure, T.I., and Miner, B.G. (2016). Decreased temperature facilitates short-term sea star wasting disease survival in the keystone intertidal sea star Pisaster ochraceus. PLoS One 11, e0153670.

Konar, B., Mitchell, T.J., Iken, K., Coletti, H., Dean, T., Esler, D., Lindeberg, M., Pister, B., and Weitzman, B. (2019). Wasting disease and static environmental variables drive sea star assemblages in the Northern Gulf of Alaska. J Exper Mar Biol Ecol 520, 151209.

Krumhansl, K.A., and Scheibling, R.E. (2012). Production and fate of kelp detritus. Mar Ecol Progr Ser 467, 281-302. 
Legrand, T., Catalano, S.R., Wos-Oxley, M.L., Stephens, F., Landos, M., Bansemer, M.S., Stone, D.a.J., Qin, J.G., and Oxley, A.P.A. (2018). The inner workings of the outer surface: Skin and gill microbiota as indicators of changing gut health in Yellowtail Kingfish. Front Microbiol 8, 17.

Leising, A.W., Schroeder, I.D., Bograd, S.J., Bjorkstedt, E.O., Field, J., Sakuma, K., Abell, J., Robertson, R.R., Tuberczy, J., and Al., E. (2014). State of the caliofrnia current 20132014: El Nino Looming. CalCOFI Report 55, 51-87.

Leslie, H.M., Breck, E.N., Chan, F., Lubchenco, J., and Menge, B.A. (2005). Barnacle reproductive hotspots linked to nearshore ocean conditions. Proc Nat Acad Sci USA 102, 10534-10539.

Levin, L.A. (2003). Oxygen minimum zone benthos: Adaptation and community response to hypoxia. Oceanogr Mar Biol Ann Rev 41, 1-45.

Levin, L.A., Ekau, W., Gooday, A.J., Jorissen, F., Middelburg, J.J., Naqvi, S.W.A., Neira, C., Rabalais, N.N., and Zhang, J. (2009). Effects of natural and human-induced hypoxia on coastal benthos. Biogeosciences 6, 2063-2098.

Lloyd, M.M., and Pespeni, M.H. (2018). Microbiome shifts with onset and progression of sea star wasting disease revealed through time course sampling. Sci Rep 8, 12.

Lozupone, C., Lladser, M.E., Knights, D., Stombaugh, J., and Knight, R. (2011). UniFrac: an effective distance metric for microbial community comparison. ISME J 5, 169-172.

Mcmurdie, P.J., and Holmes, S. (2013). phyloseq: An R package for reproducible interactive analysis and graphics of microbiome census data. PLoS One 8, e61217.

Mcmurdie, P.J., and Holmes, S. (2014). Waste not, want not: why rarefying microbiome data is inadmissible. PLoS Comput Biol 10, e1003531.

Mead, A.D. (1898). "Twenty-eighth Annual Report of the Commissioners of Inland Fisheries, Made to the General Assembly at Its January Session, 1898", (eds.) J.M.K. Southwick, H.T. Root, C.W. Willard, W.M.P. Morton, A.D. Roberts \& H.C. Bumpus.).

Melroy, L.M., Smith, R.J., and Cohen, C.S. (2017). Phylogeography of direct-developing sea stars in the genus Leptasterias in relation to San Francisco Bay outflow in central California. Mar Biol 164. 
Menge, B.A. (1975). Brood or broadcast? The adaptive significance of different reproductive strategies in the two intertidal sea stars Leptasterias hexactis and Pisaster ochraceus. Mar Biol 31, 87-100.

Menge, B.A., Cerny-Chipman, E.B., Johnson, A., Sullivan, J., Gravem, S., and Chan, F. (2016). Sea star wasting disease in the keystone predator Pisaster ochraceus in Oregon: Insights into differential population impacts, recovery, predation rate, and temperature effects from long-term research. PLoS One 11, e0153994.

Meyer, J.L., Castellanos-Gell, J., Aeby, G.S., Häse, C.C., Ushijima, B., and Paul, V.J. (2019). Microbial community shifts associated with the ongoing stony coral tissue loss disease outbreak on the Florida Reef Tract. Front Microbiol 10.

Miner, C.M., Burnaford, J.L., Ambrose, R.F., Antrim, L., Bohlmann, H., Blanchette, C.A., Engle, J.M., Fradkin, S., Gaddam, R., Hardley, C.D.G., Miner, B.G., Murray, S.N., Smith, J.R., Whitaker, S.G., and Raimondi, P.T. (2018). Large-scale impacts of sea star wasting disease (SSWD) on intertidal sea stars and implications for recovery. PLoS One 13, e0192870.

Mironov, A.N., Dilman, A.B., Vladychenskaya, I.P., and Petrov, N.B. (2016). Adaptive strategy of the Porcellanasterid sea stars. Biol Bull 43, 503-516.

Montecino-Latorre, D., Eisenlord, M.E., Turner, M., Yoshioka, R., Harvell, C.D., PattengillSemmens, C.V., Nichols, J.D., and Gaydos, J.K. (2016). Devastating transboundary impacts of sea star wasting disease on subtidal asteroids. PLoS One 11, e0163190.

Moore, S.K., Stark, K., Bos, J., Williams, P., Newton, J., and Dzinbal, K. (2014). "Puget sound marine waters: 2013 overview.", P.S.E.M.P.M.W. Workgroup. (Seattle, Washington).

Murphy, R.R., Kemp, W.M., and Ball, W.P. (2011). Long-term trends in Chesapeake Bay seasonal hypoxia, stratification, and nutrient loading. Estuaries Coasts 34, 1293-1309.

Nakagawa, S., Saito, H., Tame, A., Hirai, M., Yamaguchi, H., Sunata, T., Aida, M., Muto, H., Sawayama, S., and Takaki, Y. (2017). Microbiota in the coelomic fluid of two common coastal starfish species and characterization of an abundant Helicobacter-related taxon. Sci Rep 7, 8764.

Nakajima, R., Haas, A.F., Silveira, C.B., Kelly, E.L.A., Smith, J.E., Sandin, S., Kelly, L.W., Rohwer, F., Nakatomi, N., and Kurihara, H. (2018). Release of dissolved and particulate 
organic matter by the soft coral Lobophytum and subsequent microbial degradation. $J$ Exper Mar Biol Ecol 504, 53-60.

Nance, J.M. (1981). Respiratory water flow and production of mucus in the cushion star,

1175

1176

1177

1178

1179

1180

1181

1182

1183 Pteraster tesselatus Ives (Echinodermata: Asteroidea). J Exper Mar Biol Ecol 50, 21-31.

Nepf, H.M. (2011). "2.13 - Flow Over and Through Biota," in Treatise on Estuarine and Coastal Science, eds. E. Wolanski \& D. Mclusky. (Waltham: Academic Press), 267-288.

Noble, R.T., and Fuhrman, J.A. (1998). Use of SYBR Green I rapid epifluoresence counts of marine viruses and bacteria. Aquat Microb Ecol 14, 113-118.

Nugues, M.M., Smith, G.W., Van Hooidonk, R.J., Seabra, M.I., and Bak, R.P.M. (2004). Algal contact as a trigger for coral disease. Ecol Lett 7, 919-923.

Nunez-Pons, L., Work, T.M., Angulo-Preckler, C., Moles, J., and Avila, C. (2018). Exploring the pathology of an epidermal disease affecting a circum-Antarctic sea star. Sci Rep 8, 12.

Ochiai, M., Nakajima, T., and Hanya, T. (1980). Chemical composition of labile fractions in DOM. Hydrobiol 71, 95-97.

Ogawa, H., and Tanoue, E. (2003). Dissolved organic matter in oceanic waters. J Oceanogr 59, 129-147.

Oksanen, J., Blanchet, F.G., Friendly, M., Kindt, R., Legendre, P., Mcglinn, D., Minchin, P.R., O'hara, R.B., Simpson, G.L., Solymos, P., Stevens, M.H.H., Szoecs, E., and Wagner, H. (2019). "vegan: Community Ecology Package". R package version 2.5-6 ed.).

Olsen, A.Y., Smith, A., and Larson, S. (2016) "A temporal analysis of water quality variability at the Seattle Aquarium in Elliott Bay, Puget Sound, WA," in Water Challenges of an Urbanizing World, ed. M. Glavan. (DOI: 10.5772/intechopen.68339: IntechOpen), 5569.

Patterson, H.K., and Carmichael, R.H. (2018). Dissolved oxygen concentration affects $\delta 15 \mathrm{~N}$ values in oyster tissues: implications for stable isotope ecology. Ecosphere 9, e02154.

Pinhassi, J., Sala, M.M., Havskum, H., Peters, F., Guadayol, Ò., Malits, A., and Marrasé, C. (2004). Changes in bacterioplankton composition under different phytoplankton regimens. Appl Environ Microbiol 70, 6753-6766.

Piruat, J.I., and López-Barneo, J. (2005). Oxygen tension regulates mitochondrial DNA-encoded complex I gene expression. J Biol Chem 280, 42676-42684. 
Pohlner, M., Dlugosch, L., Wemheuer, B., Mills, H., Engelen, B., and Reese, B.K. (2019). The majority of active Rhodobacteraceae in marine sediments belong to uncultured genera: A molecular approach to link their distribution to environmental conditions. Front Microbiol 10.

Porter, K.G., and Feig, Y.S. (1980). The use of DAPI for identifying and counting aquatic microflora. Limnol Oceanogr 25, 943-948.

Preisig, O., Zufferey, R., Thöny-Meyer, L., Appleby, C.A., and Hennecke, H. (1996). A highaffinity cbb3-type cytochrome oxidase terminates the symbiosis-specific respiratory chain of Bradyrhizobium japonicum. J Bacteriol 178, 1532-1538.

Propp, M.V., Ryabushko, V.I., Zhuchikhina, A.A., and Propp, L.N. (1983). Seasonal changes in respiration, ammonia and phosphate excretion, and activity of carbohydrate-metabolism enzymes in four echinoderm species from the sea of Japan. Comp Biochem Physiol B 75, 707-711.

Quast, C., Pruesse, E., Yilmaz, P., Gerken, J., Schweer, T., Yarza, P., Peplies, J., and Glöckner, F.O. (2012). The SILVA ribosomal RNA gene database project: improved data processing and web-based tools. Nucl Acid Res 41, D590-D596.

Reverter, M., Sasal, P., Tapissier-Bontemps, N., Lecchini, D., and Suzuki, M. (2017). Characterisation of the gill mucosal bacterial communities of four butterflyfish species: a reservoir of bacterial diversity in coral reef ecosystems. FEMS Microb Ecol 93, 10.

Roach, T.N.F., Abieri, M.L., George, E.E., Knowles, B., Naliboff, D.S., Smurthwaite, C.A., Kelly, L.W., Haas, A.F., and Rohwer, F.L. (2017). Microbial bioenergetics of coral-algal interactions. PeerJ 5, e3423.

Robinson, J.D., Mann, K.H., and Novitsky, J.A. (1982). Conversion of the particulate fraction of seaweed detritus to bacterial biomass. Limnol Oceanogr 27, 1072-1079.

Rosado, D., Pérez-Losada, M., Severino, R., Cable, J., and Xavier, R. (2019). Characterization of the skin and gill microbiomes of the farmed seabass (Dicentrarchus labrax) and seabream (Sparus aurata). Aquaculture 500, 57-64.

Ruiz-Ramos, D.V., Schiebelhut, L.M., Hoff, K.J., Wares, J.P., and Dawson, M.N. (2020). An initial comparative genomic autopsy of wasting disease in sea stars. Molec Ecol 29, 10871102. 
Santoro, A.E., Nidzieko, N.J., Dijken, G.L.V., Arrigo, K.R., and Boehma, A.B. (2010). Contrasting spring and summer phytoplankton dynamics in the nearshore Southern California Bight. Limnol Oceanogr 55, 264-278.

Sato, Y., Ling, E.Y.S., Turaev, D., Laffy, P., Weynberg, K.D., Rattei, T., Willis, B.L., and Bourne, D.G. (2017). Unraveling the microbial processes of black band disease in corals through integrated genomics. Sci Rep 7, 40455.

Schiebelhut, L.M., Puritz, J.B., and Dawson, M.N. (2018). Decimation by sea star wasting disease and rapid genetic change in a keystone species, Pisaster ochraceus. Proc Nat Acad Sci USA 115, 7069-7074.

Schultz, J.A., Cloutier, R.N., and Cote, I.M. (2016). Evidence for a trophic cascade on rocky reefs following sea star mass mortality in British Columbia. PeerJ 4, 19.

Sharma, S., Singh, S., Gupta, R., Ganju, L., Singh, S., Kumar, B., and Singh, Y. (2019). Mitochondrial DNA sequencing reveals association of variants and haplogroup M33a2'3 with High altitude pulmonary edema susceptibility in Indian male lowlanders. Sci Rep 9.

Shibata, A., Goto, Y., Saito, H., Kikuchi, T., Toda, T., and Taguchi, S. (2006). Comparison of SYBR Green I and SYBR Gold stains for enumerating bacteria and viruses by epifluorescence microscopy. Aquat Microb Ecol 43, 223-231.

Shick, J.M. (1976). Physiological and behavioral responses to hypoxia and hydrogen sulfide in the infaunal asteroid Ctenodiscus crispatus. Mar Biol 37, 279-289.

Shick, J.M., Edwards, K.C., and Dearborn, J.H. (1981). Physiological ecology of the deposit feeding sea star Ctenodiscus cripsatus - ciliated surfaces and animal-sediment interactions. Mar Ecol Progr Ser 5, 165-184.

Siebers, D. (1979). Transintegumentary uptake of dissolved amino acids in the sea star Asterias rubens - Reassessment of its nutritional role with special reference to the significance of heterotrophic bacteria. Mar Ecol Progr Ser 1, 169-177.

Siebers, D. (2015). Bacterial—invertebrate interactions in uptake of dissolved organic matter. Amer Zool 22, 723-733.

Silveira, C.B., Luque, A., Roach, T.N.F., Villela, H., Barno, A., Green, K., Reyes, B., Esther, R.P., Le, T., Mead, S., Hatay, M., Bermeij, M.J., Takeshita, Y., Haas, A.F., Bailey, B., and Rohwer, F. (2019). Biophysical and physiological processes causing oxygen loss from coral reefs. eLife 8, e49114. 
Silverman, J.D., Washburne, A.D., Mukherjee, S., and David, L.A. (2017). A phylogenetic transform enhances analysis of compositional microbiota data. eLife 6, e21887.

Smith, J.E., Shaw, M., Edwards, R.A., Obura, D., Pantos, O., Sala, E., Sandin, S.A., Smriga, S., Hatay, M., and Rohwer, F.L. (2006). Indirect effects of algae on coral: algae-mediated, microbe-induced coral mortality. Ecol Lett 9, 835-845.

Spence, C.D., Vanaudenaerde, B., Einarsson, G.G., Mcdonough, J., Lee, A.J., Johnston, E., Verleden, G.M., Elborn, J.S., Dupont, L.J., Van Herck, A., Gilpin, D.F., Vos, R., Tunney, M.M., and Verleden, S.E. (2020). Influence of azithromycin and allograft rejection on the post-lung transplant microbiota. J Heart Lung Transplant 39, 176-183.

Suchy, K.D., Le Baron, N., Hilborn, A., Perry, R.I., and Costa, M. (2019). Influence of environmental drivers on spatio-temporal dynamics of satellite-derived chlorophyll a in the Strait of Georgia. Progr Oceanogr 176, 102134.

Thiele, S., Richter, M., Balestra, C., Glöckner, F.O., and Casotti, R. (2017). Taxonomic and functional diversity of a coastal planktonic bacterial community in a river-influenced marine area. Mar Genom 32, 61-69.

Thornton, D.C.O. (2014). Dissolved organic matter (DOM) release by phytoplankton in the contemporary and future ocean. Eur J Phycol 49, 20-46.

Tobler, M., Henpita, C., Bassett, B., Kelley, J.L., and Shaw, J.H. (2014). H${ }_{2}$ S exposure elicits differential expression of candidate genes in fish adapted to sulfidic and non-sulfidic environments. Comp Bioechem and Physiol A 175, 7-14.

Van Alstyne, K.L. (2016). Seasonal changes in nutrient limitation and nitrate sources in the green macroalga Ulva lactuca at sites with and without green tides in a northeastern Pacific embayment. Mar Poll Bull 103, 186-194.

Vander Zanden, M.J., Clayton, M.K., Moody, E.K., Solomon, C.T., and Weidel, B.C. (2015). Stable isotope turnover and half-life in animal tissues: A literature synthesis. PLoS One 10, e0116182.

Vistisen, B., and Vismann, B. (1997). Tolerance to low oxygen and sulfide in Amphiura filiformis and Ophiura albida (Echinodermata: Ophiuroidea). Mar Biol 128, 241-246.

Wang, K., Huang, Y., Zhang, Z., Liao, J., Ding, Y., Fang, X., Liu, L., Luo, J., and Kong, J. (2019). A preliminary study of microbiota diversity in saliva and bronchoalveolar lavage fluid from patients with primary bronchogenic carcinoma. Med Sci Monit 25, 2819-2834. 
1293 Washburne, A.D., Silverman, J.D., Leff, J.W., Bennett, D.J., Darcy, J.L., Mukherjee, S., Fierer, 1294 N., and David, L.A. (2017). Phylogenetic factorization of compositional data yields lineage-level associations in microbiome datasets. PeerJ 5, e2969.

1296 Wu, Y., Klapper, I., and Stewart, P.S. (2018). Hypoxia arising from concerted oxygen

1297 consumption by neutrophils and microorganisms in biofilms. Pathogen Dis 76, fty043.

1298 Zhang, T., and Wang, X. (2017). Release and microbial degradation of dissolved organic matter 1299 (DOM) from the macroalgae Ulva prolifera. Mar Pollut Bull 125, 192-198. 

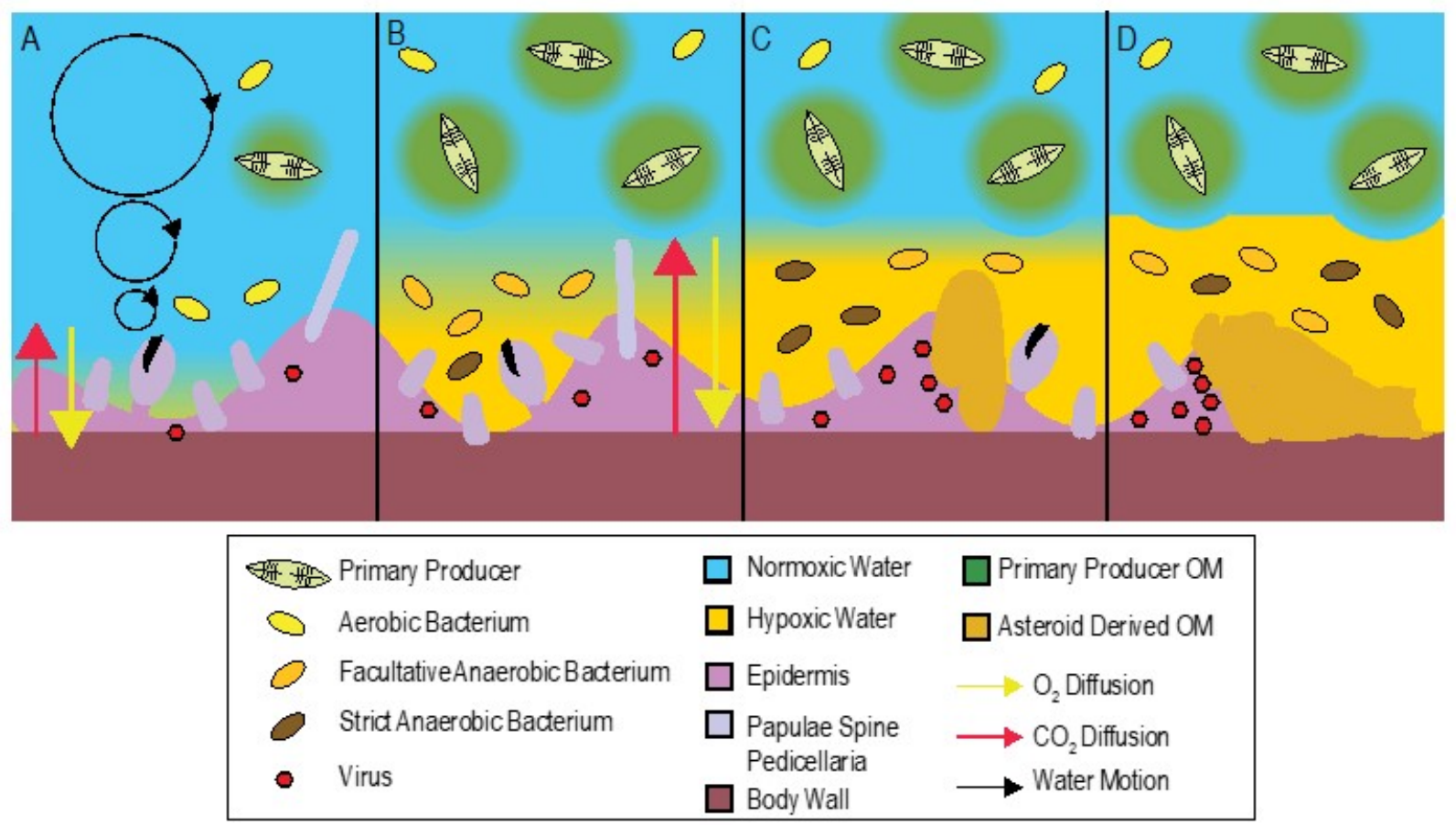

Fig. 1: Conceptualization of BLODL. Under typical conditions (A), boundary layer conditions are normoxic because of limited dissolved organic matter inputs, and consequently lower heterotrophic bacterial respiration. When organic matter (possibly from primary production) increases in surrounding waters (B; e.g. during heightened primary productivity, from terrestrial runoff, or from decaying asteroid carcasses), this stimulates bacterial heterotrophic respiration and abundance and results in the formation of suboxic waters within the limited water motion boundary layer, which in turn results in longer distances over which diffusion must occur to maintain animal respiratory demand. Over time (C) suboxic conditions in the boundary layer results in tissue damage, and prevalence of strict and facultative anaerobes. Because their growth

1313 is less efficient than aerobic metabolisms their abundance is less than at hypoxia onset. Release 1314 of labile organic matter from decaying tissues (D) and persistent organic-matter rich conditions 1315 within the asteroid boundary layer result in animal mortality. 


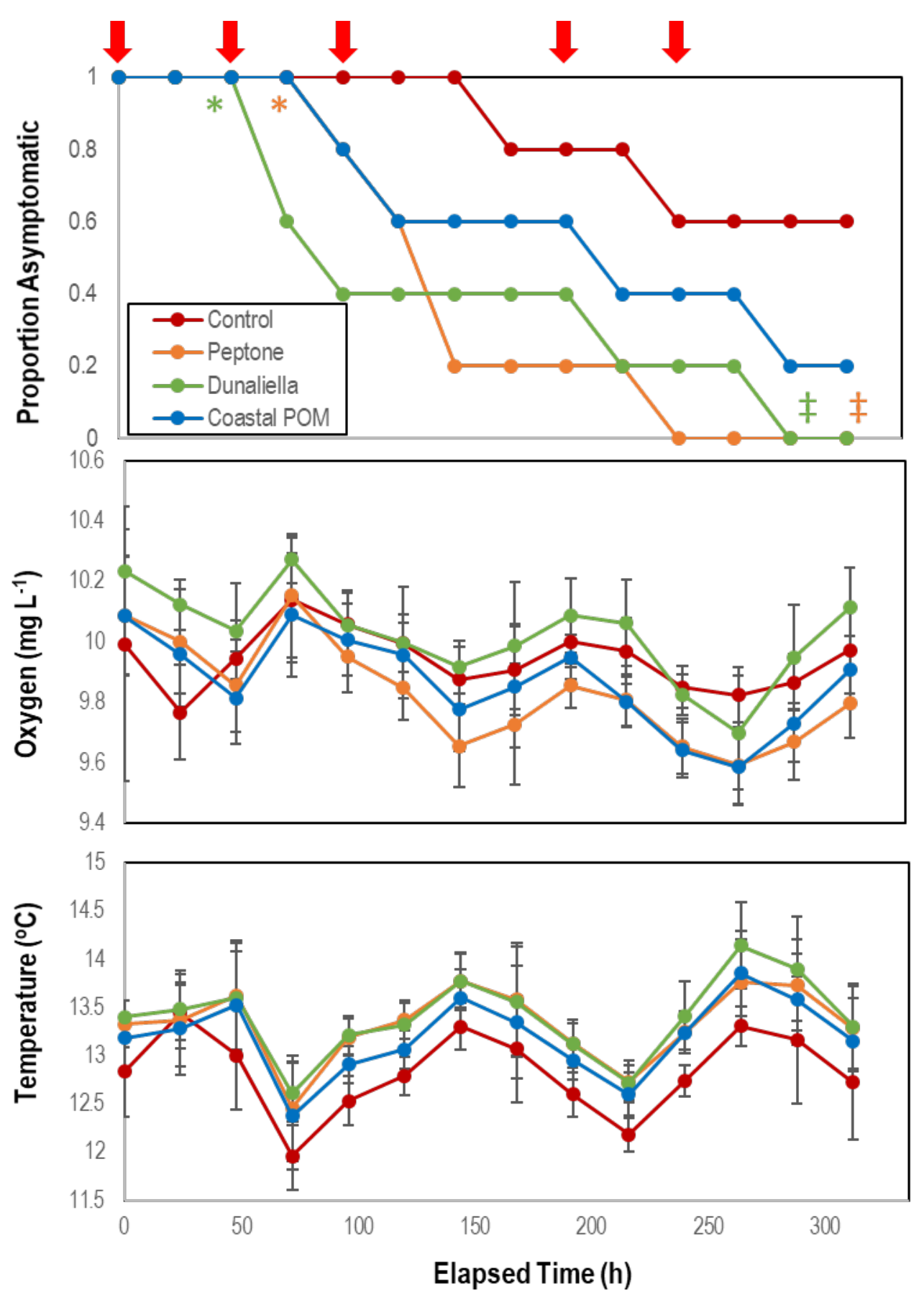

1319 Fig 2: Proportion of asymptomatic $P$. ochraceus (n = 5 each treatment) incubated in flow-

1320 through conditions at the Bodega Marine Lab in response to organic matter enrichments

1321 (Peptone, Dunaliella tertiolecta culture POM, and coastal POM collected from the inflow at the

1322 Bodega Marine Laboratory in August 2019. Dissolved $\mathrm{O}_{2}$ and temperature were measured in

1323 flow-through sea tables bearing each OM treatment. Error Bars = SD. The red arrows above the 1324 top panel indicate sampling for microbiome analyses. * indicates wasting speed (i.e. time to 
bioRxiv preprint doi: https://doi.org/10.1101/2020.07.31.231365; this version posted September 27, 2020. The copyright holder for this preprint (which was not certified by peer review) is the author/funder, who has granted bioRxiv a license to display the preprint in perpetuity. It is made available under aCC-BY-NC-ND 4.0 International license.

1325 appearance of first lesion) was significantly ( $<<0.05$, Student’s t-test) faster than control. $\ddagger$ 1326 indicates that the the overall trend in lesion formation was significantly different to controls $(\mathrm{p}<$ $1327 \quad 0.05$, log-rank test). 
bioRxiv preprint doi: https://doi.org/10.1101/2020.07.31.231365; this version posted September 27, 2020. The copyright holder for this preprint (which was not certified by peer review) is the author/funder, who has granted bioRxiv a license to display the preprint in perpetuity. It is made available under aCC-BY-NC-ND 4.0 International license.
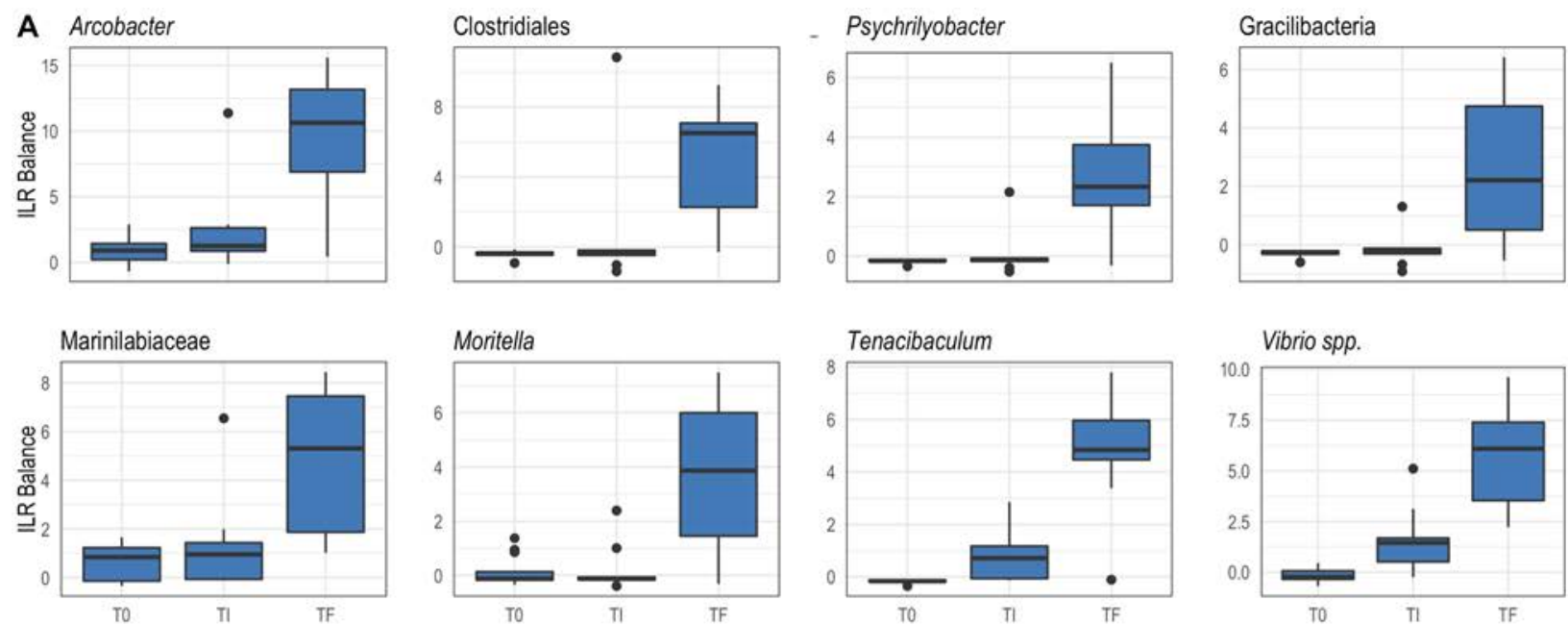

B
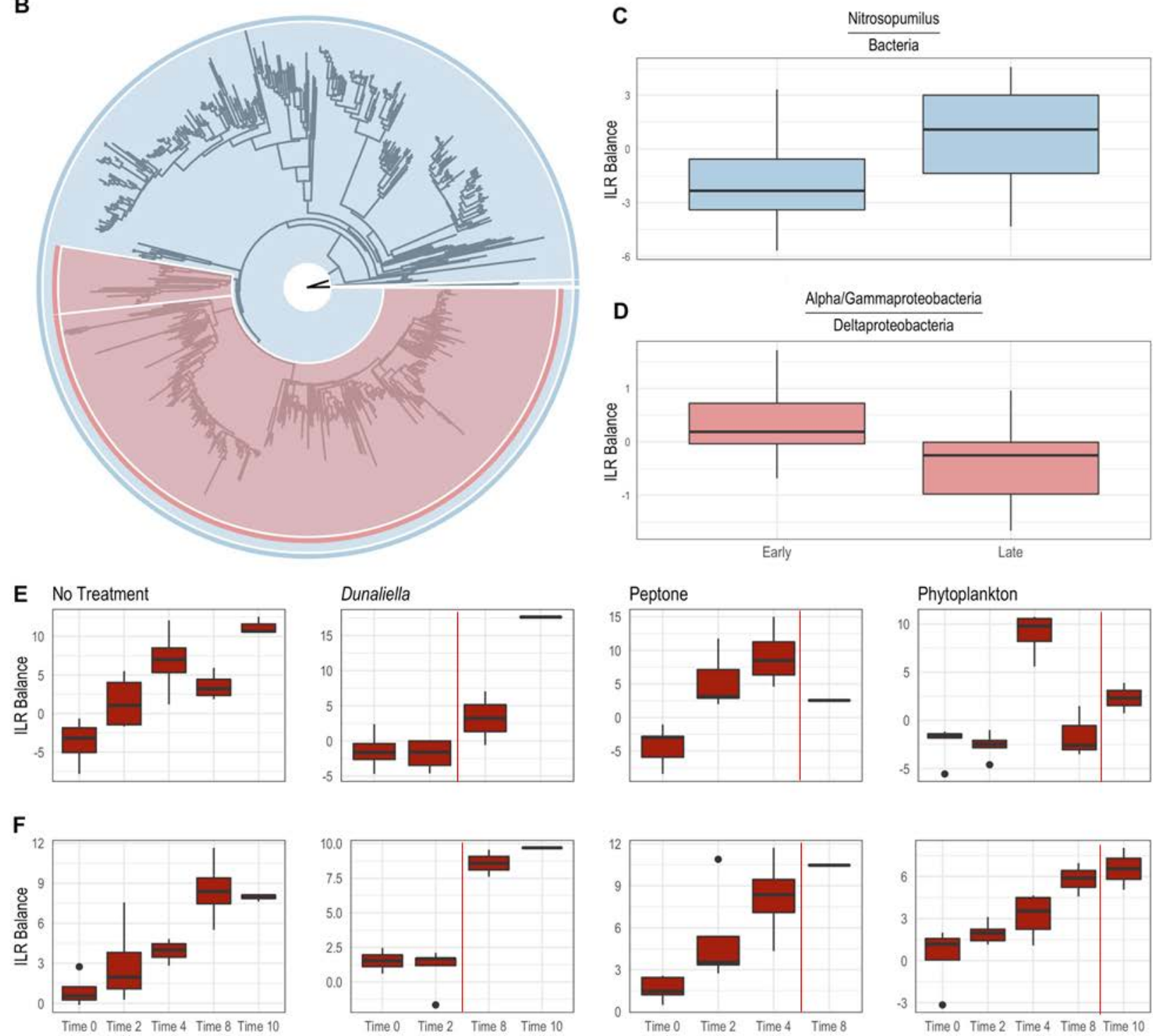
1329 Fig. 3: Differential abundance of bacterial taxa from body wall samples (A; P. ochraceus June 2018) and surface swabs (B-F; P. ochraceus August 2019). (A) Boxplots were derived using PhyloFactor (Washburne et al. 2017), which uses a generalized linear model to regress the isometric log-ratio (ILR balance) between opposing clades (contrasted by an edge) on a phylogenetic tree. This was done iteratively, with each iteration, or factor, maximizing the $\mathrm{F}$ statistic from regression. Shown taxa represent either a single factor or combination of factors (when, for example, multiple factors identified different sOTUs with the same taxonomic classification). Labels represent either the highest taxonomic resolution or the highest classification shared by all sOTUs of a given clade. $\mathrm{T} 0=$ experiment commencement, $\mathrm{TI}=$ lesion genesis, TF = time of death. (B-D) Balance contrast of early (before lesion genesis) samples compared to late (immediately prior to lesion genesis) samples. Samples were transformed using the Phylogenetic Isometric Log-Ratio (PhILR; Silverman et al. 2017) transform, which uses a phylogenetic tree (B) to convert an sOTU table into a new matrix of coordinates derived from the ILR of clades that descend from a common node. We used a sparse logistic regression with an $l_{1}$ penalty of $\lambda=0.15$ (Silverman et al. 2017) to analyze the ILR at each node, and included a select number of 'balances' with positive coefficients (C-D). (C) is the balance of Nitrosopumilus (colored blue in (B), comprises the thin sliver on the right side of the tree) relative to the rest of the dataset (also shown in blue in (B)). A positive shift indicates an increase in Nitrosopumilus relative to its denominator. (D) is the balance between a clade of Alpha/Gammaproteobacteria 1348 (large, red clade in (B)) and Deltaproteobacteria (Bdellovibrionales and Desulfobacterales; small, red clade in (B)). A negative shift indicates that the denominator, Deltaproteobacteria, is increasing relative to Alpha/Gammaproteobacteria. (E) and (F) were derived from a PhyloFactor object and show the ILR balance of Flavobacteriales (E) and Rhodobacterales (F) relative to all other sOTUs. Organic amendment is given above boxplots. Time $0=0 \mathrm{~h}$, Time $2=48 \mathrm{~h}$, Time 4 = $96 \mathrm{~h}$; Time $8=192 \mathrm{~h}$; Time $10=240 \mathrm{~h}$. Total sample numbers for each treatment (which varied due to the loss of asteroids over the course of the experiment to wasting) is given in Fig. lesions. 

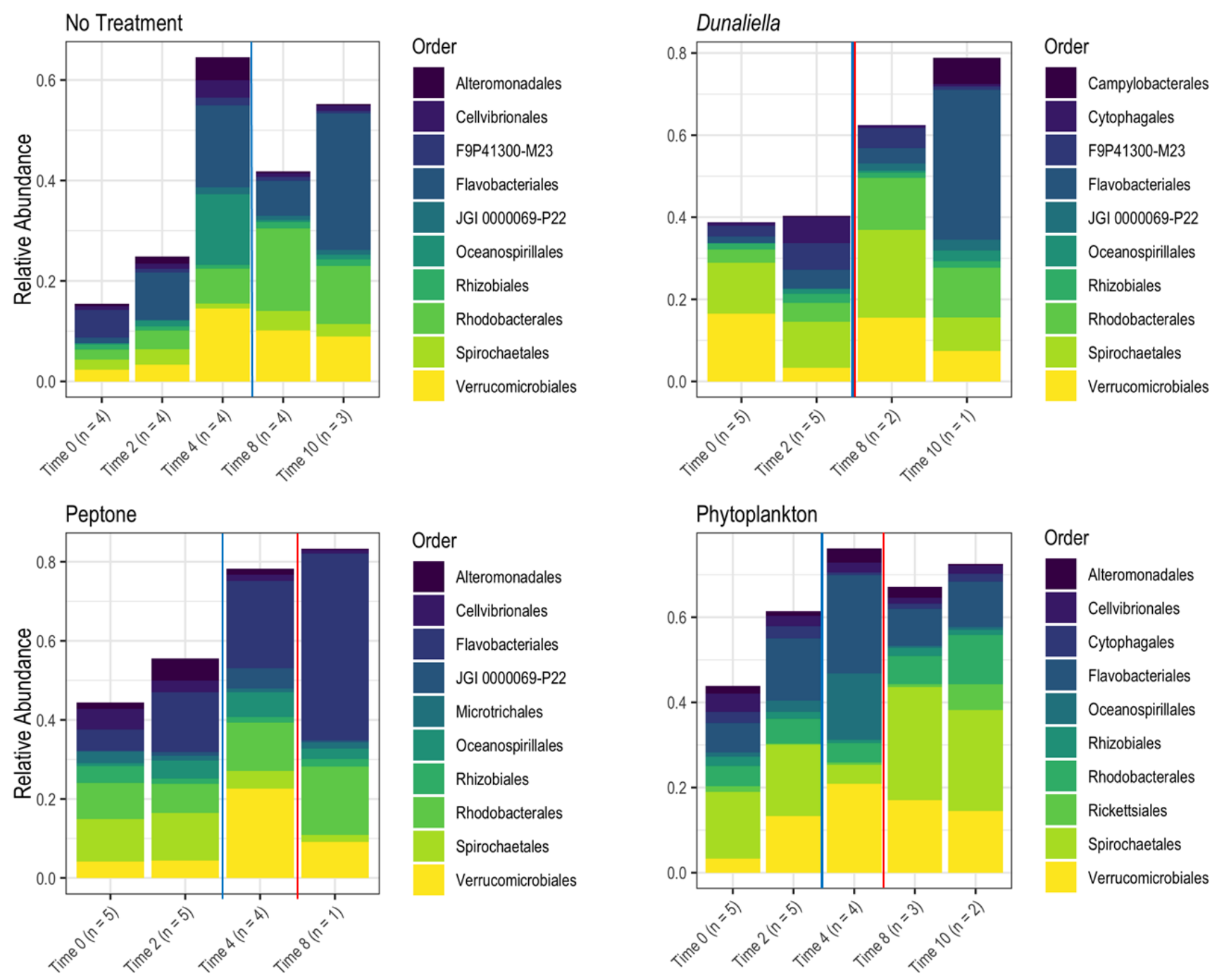

1360 Fig 4: Relative abundance of bacterial orders derived from P. ochraceus epidermal swabs.

1361 Specimens were enriched with the indicated organic material and sampled until lesion genesis.

1362 Time 0 represents initial sampling and each subsequent time indicates the respective day. $\mathrm{n}$

1363 values reflect the number of healthy specimens at each given timepoint. The solid blue line on

1364 each panel indicates when lesions first formed per treatment, and the solid red line on each panel

1365 indicates the mean lesion time within the treatment. Time $0=0 \mathrm{~h}$, Time $2=48 \mathrm{~h}$, Time $4=96 \mathrm{~h}$;

1366 Time $8=192 \mathrm{~h}$; Time $10=240 \mathrm{~h}$. 

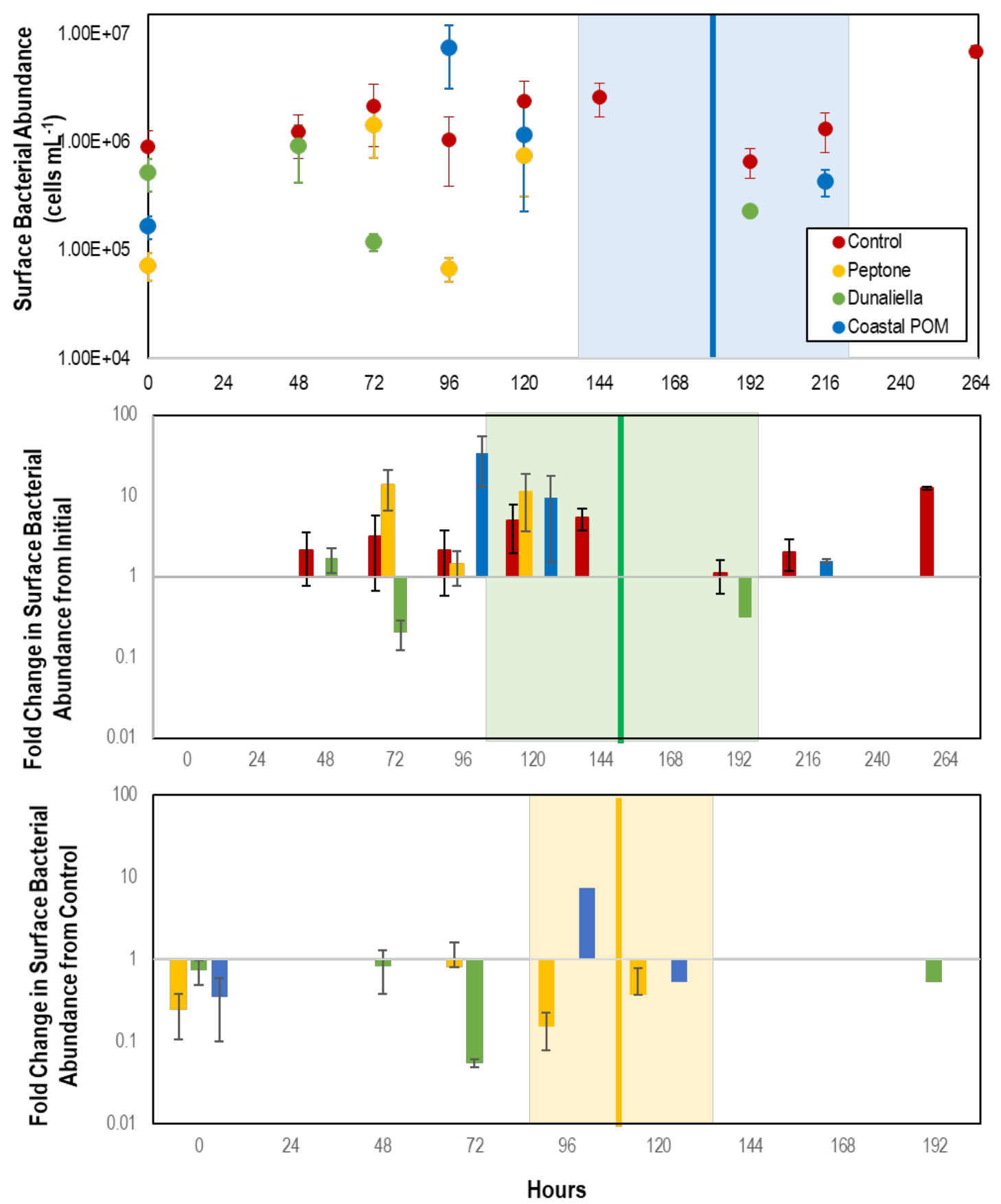

1370 Fig 5: Abundance of bacteria in proximity to $P$. ochraceus surfaces (top), percentage change 1371 from initial (middle), and relative to controls (bottom). during first 10 days of experiment in 1372 response to organic matter enrichment ( $\mathrm{n}=5$ for each treatment) as assessed by SYBR Gold 1373 staining and epifluorescence microscopy. Control specimens are indicated in red, while the mean 1374 of stars that wasted in Peptone, Dunaliella tertiolecta POM, and Coastal POM are indicated 
1375 separately. The solid vertical line on the top panel represents the mean time that asteroids

1376 developed lesions in the coastal POM treatment, the solid line on the middle panel represents the

1377 mean time for lesion development in Dunaliella tertiolecta POM treatments, and solid line on

1378 the bottom panel represents the mean time for lesion development in peptone treatments

1379 (separated between panels for clarity). The shaded regions represent lesion development standard 1380 error for respective treatments. 
bioRxiv preprint doi: https://doi.org/10.1101/2020.07.31.231365; this version posted September 27, 2020. The copyright holder for this preprint (which was not certified by peer review) is the author/funder, who has granted bioRxiv a license to display the preprint in perpetuity. It is made available under aCC-BY-NC-ND 4.0 International license.
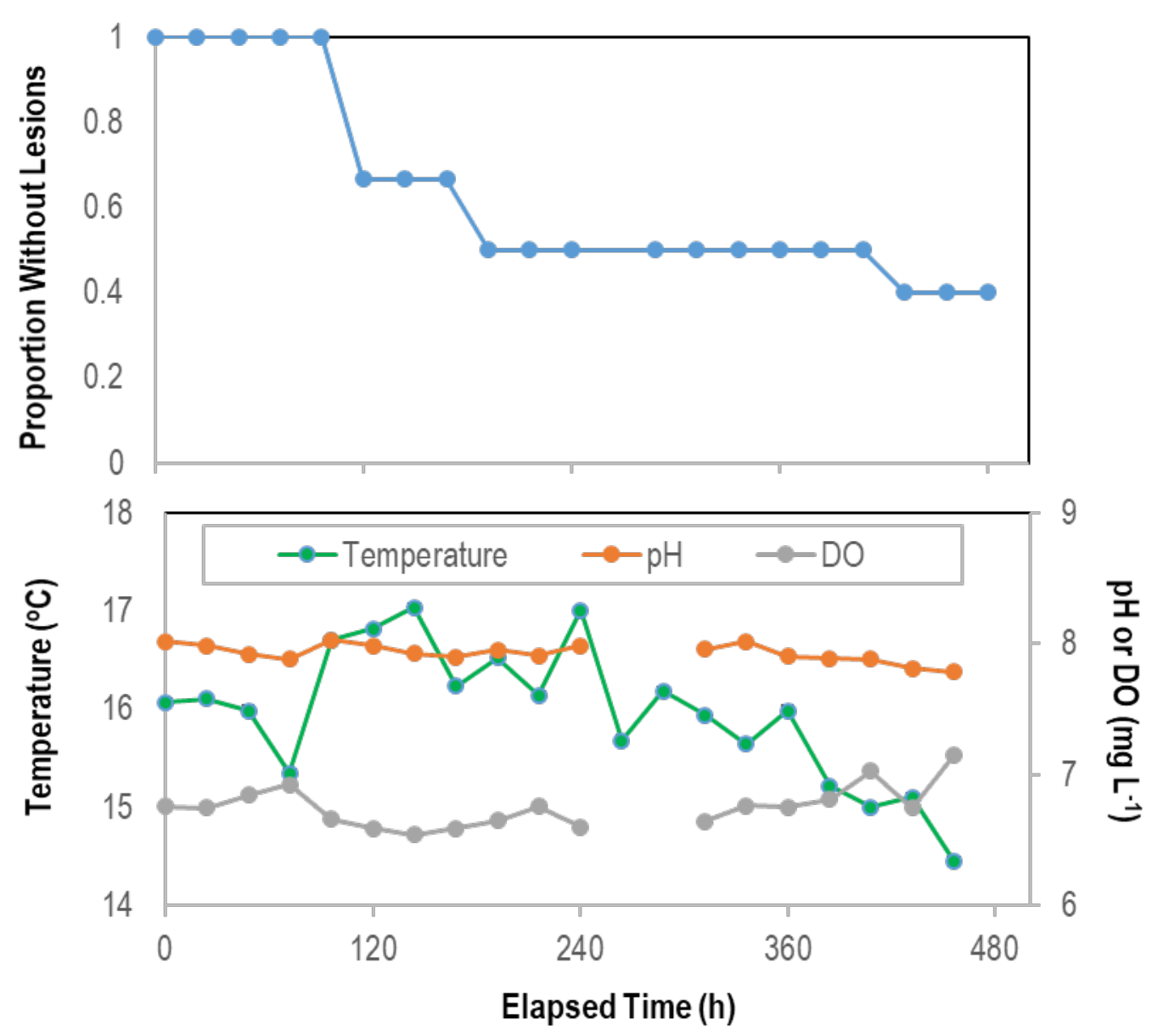

1383 Fig. 6: Proportion of asymptomatic P. ochraceus $(\mathrm{n}=5)$ remaining over time during longitudinal 1384 study of microbiome composition in the absence of external stimuli. The mean flow rate into 1385 aquariums was $3.81 \pm 0.05 \mathrm{~mL} \mathrm{~s}^{-1}$ (average residence time in aquariums $37 \mathrm{~min}$ ). 

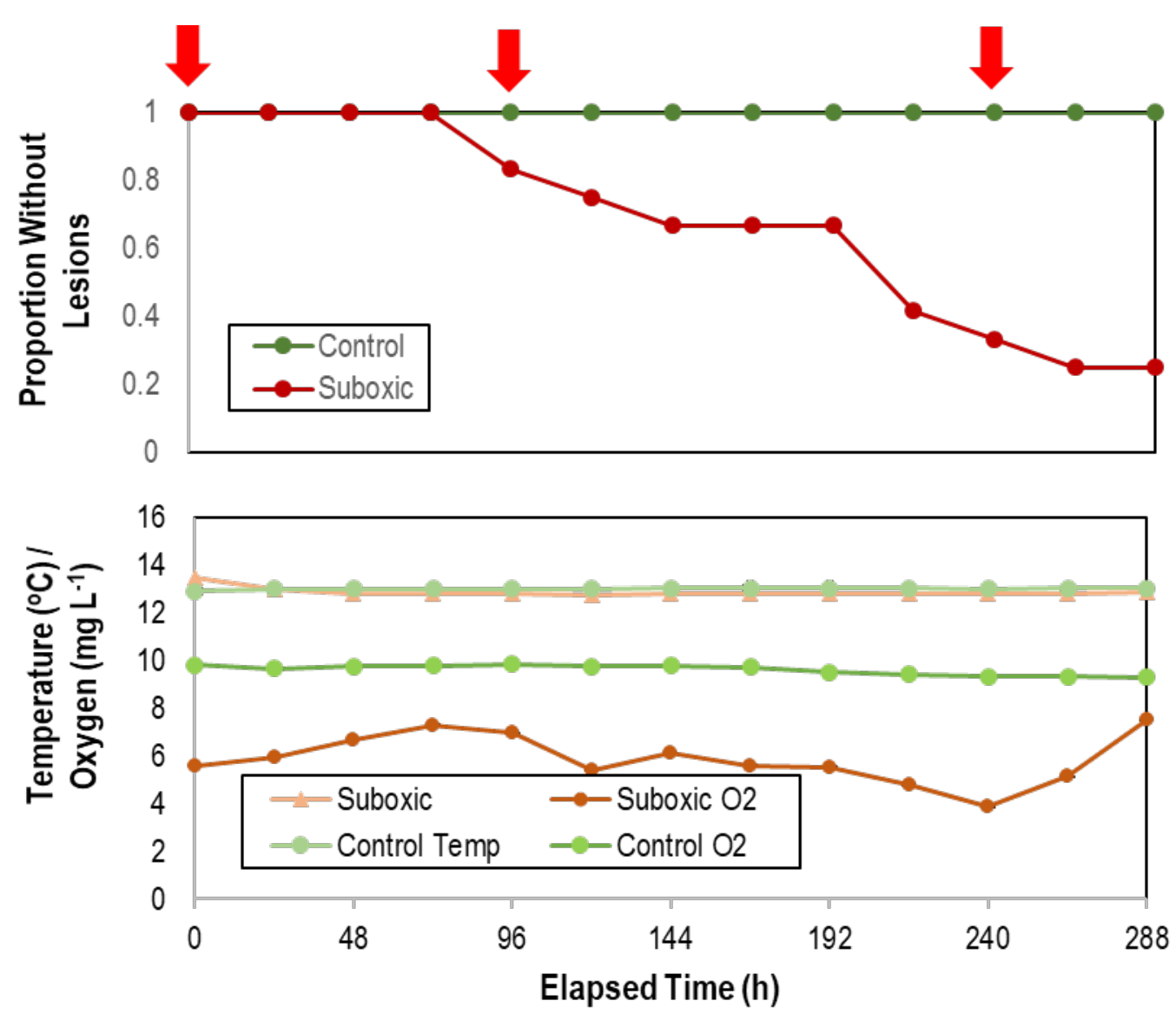

1388 Fig. 7: Proportion of asymptomatic Asterias forbesi incubated in normoxic and suboxic water 1389 (top) and variation in temperature and $\mathrm{O}_{2}$ in incubation aquaria (bottom) over time. The red 1390 arrows at top indicate samples which were included in analysis of microbiome composition (see 1391 Fig. S9). 


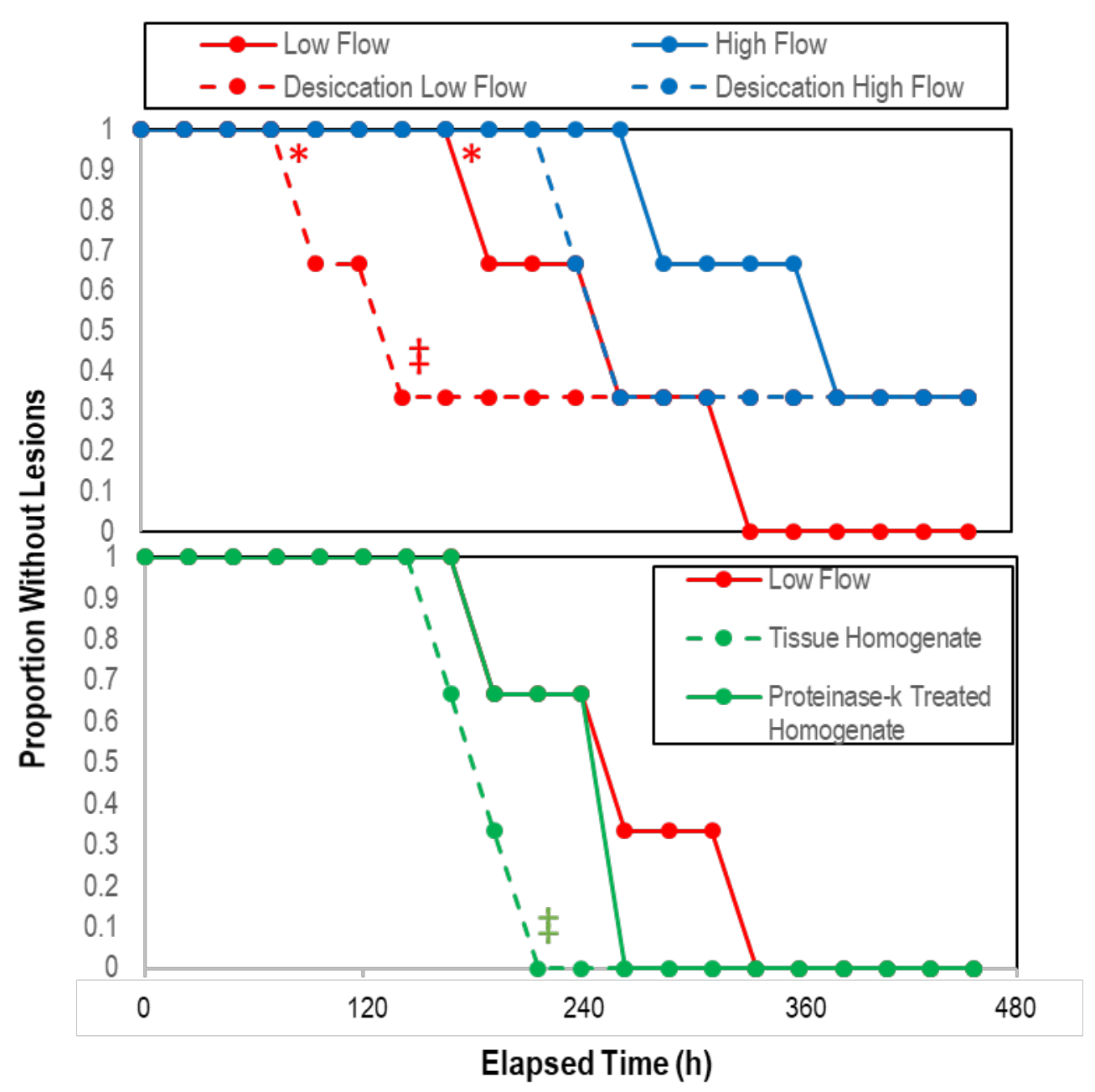

$1394 \quad$ Fig. 8: Proportion asymptomatic $P$. ochraceus over time in response to treatment (top)

1395 desiccation $(\mathrm{n}=3)$, and (bottom) treatment with crude and proteinase k-treated tissue

1396 homogenates $(\mathrm{n}=2)$. * indicates that low flow lesion genesis time was significantly $(\mathrm{p}<0.05$,

1397 Student’s t-test) compared to high flow rate; $\ddagger$ indicates that the overall trend of desiccation

1398 under low vs high flow rate and with the addition of proteinase-k treated homogenate vs low

1399 flow controls was significant ( $\mathrm{p}<0.05$, log-rank test). 

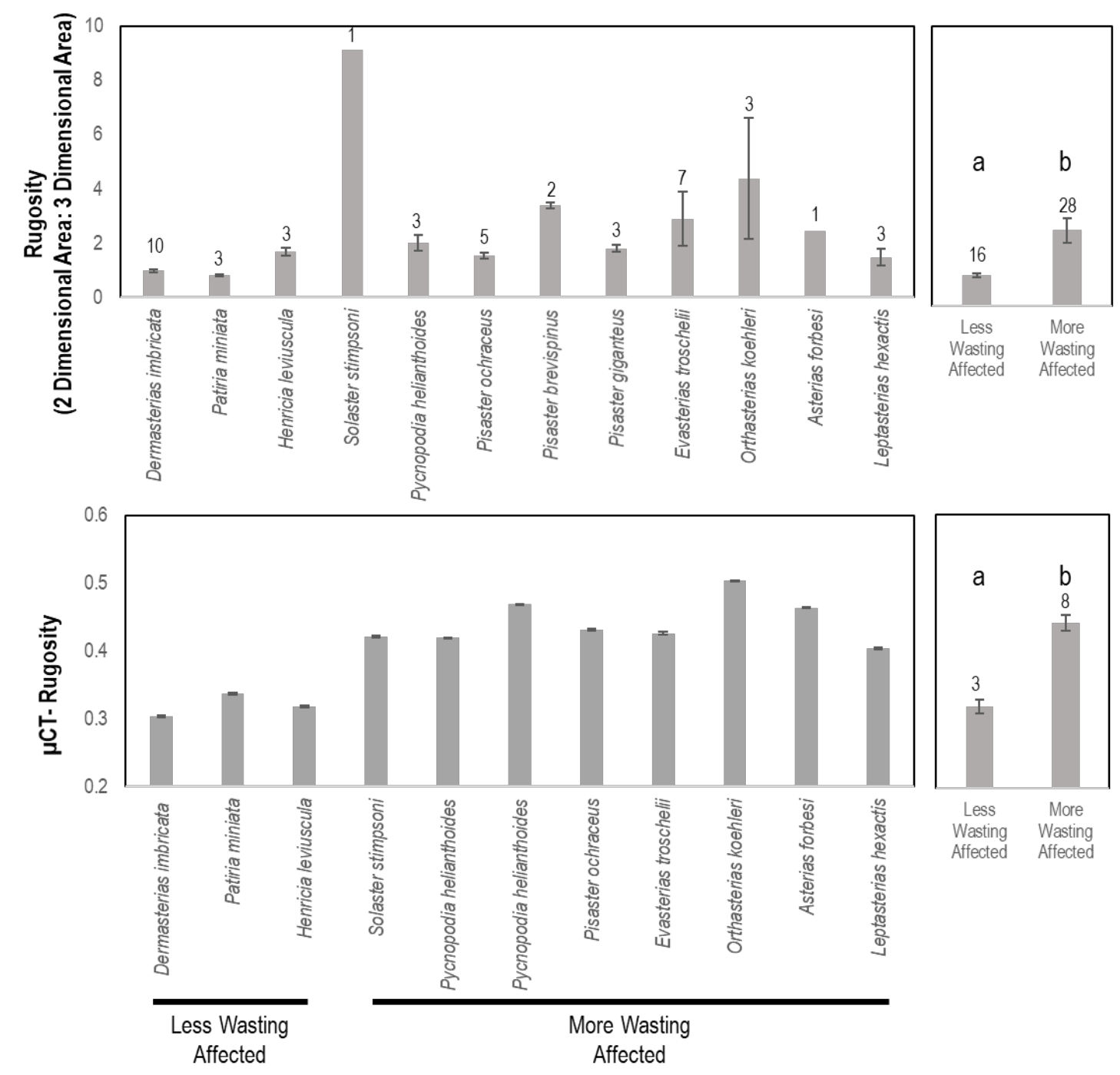

Asteroid Species

1403 Fig. 9: Rugosity of similarly-sized animals between wasting-affected and less wasting affected

1404 species as determined by whole animal computed tomography (top) and of an asteroid ray by

1405 micro-computed tomography (bottom). a, b denote significant difference at $p<0.001$. More and

1406 less wasting affected were based upon previous work and defined in the text. 


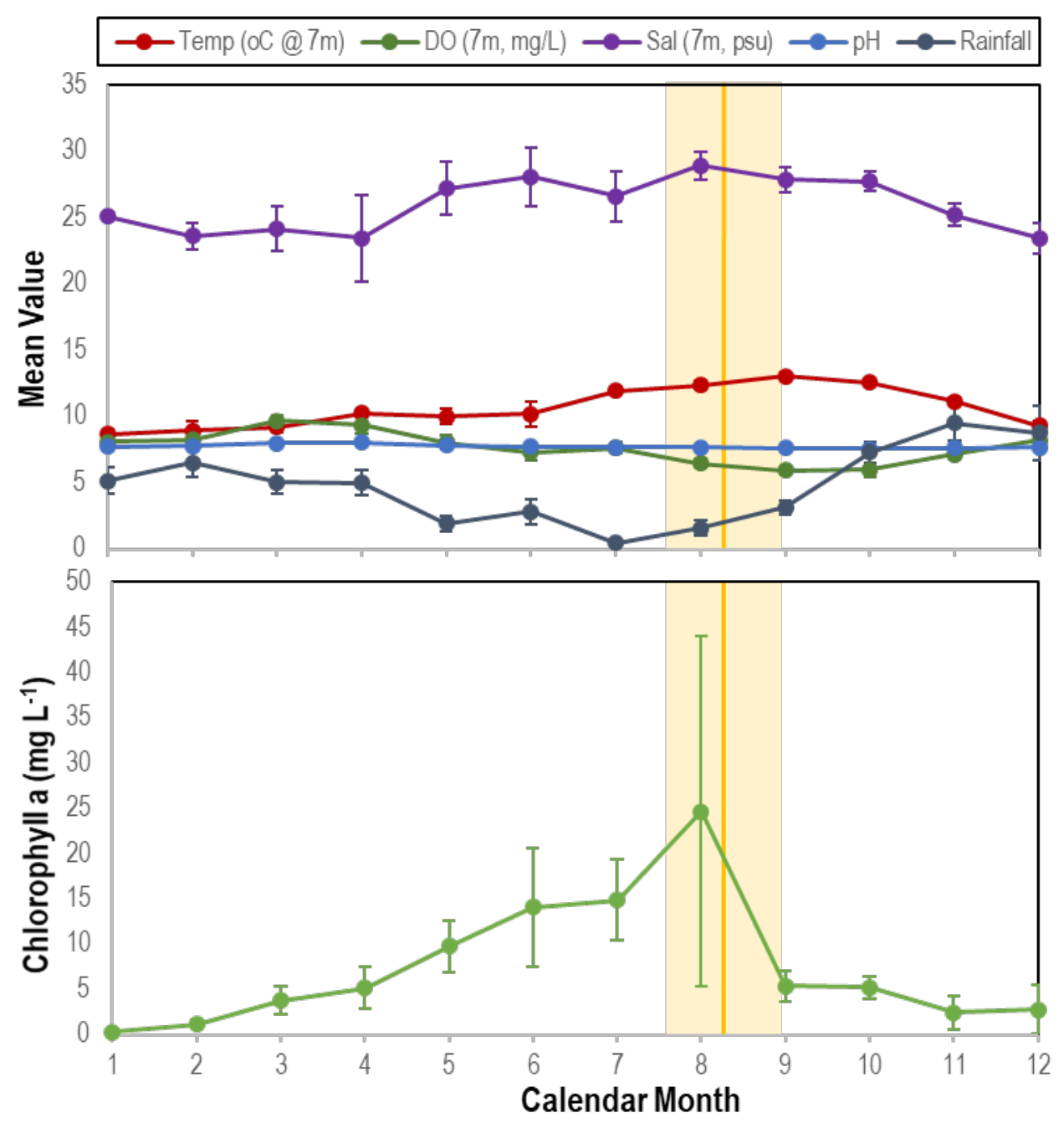

1409 Fig 10: Correspondence between mean time of wasting mass mortality (indicated by solid

1410 orange line (SE range indicated by lighter orange bar) compared with physico-chemical

1411 parameters (top) and chlorophyll a concentration (bottom) at Penn Cove, Whidbey Island from

14122014 - 2019. Temp = temperature; DO = dissolved oxygen; Sal = salinity. 
bioRxiv preprint doi: https://doi.org/10.1101/2020.07.31.231365; this version posted September 27,2020 . The copyright holder for this preprint (which was not certified by peer review) is the author/funder, who has granted bioRxiv a license to display the preprint in perpetuity. It is made available under aCC-BY-NC-ND 4.0 International license.

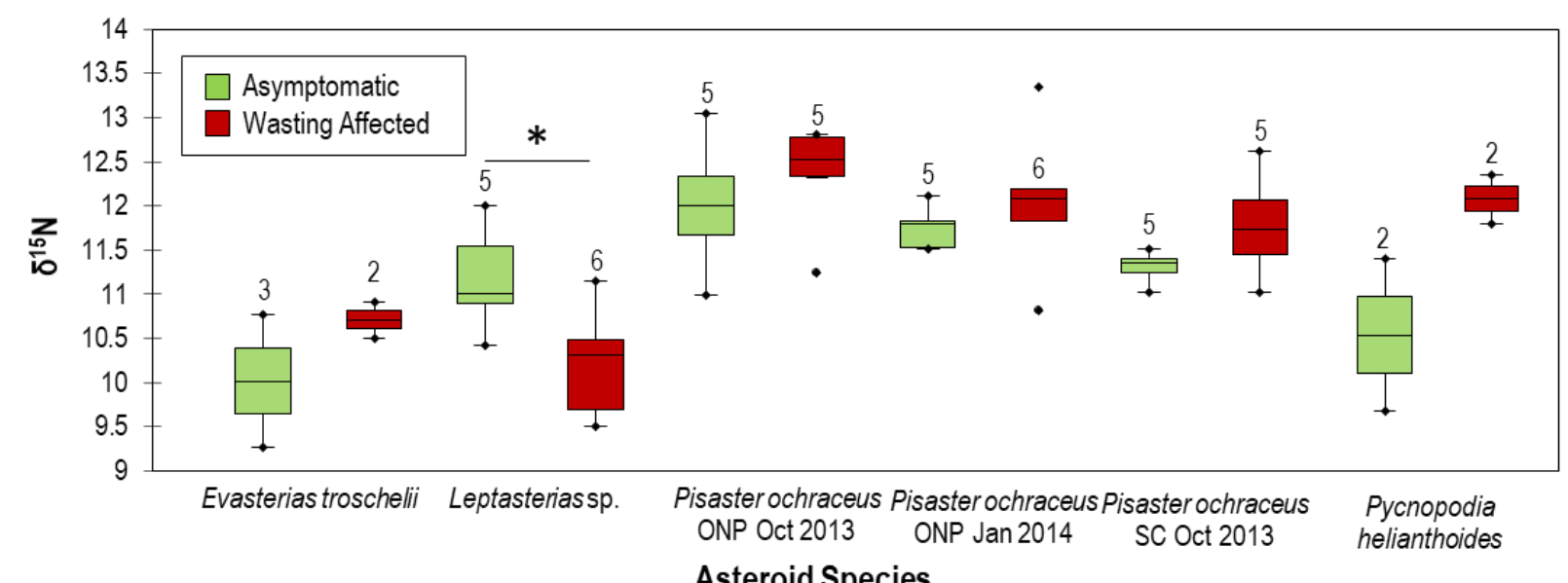

1415 Fig. 11: Comparison of asymptomatic and wasting $\delta^{15} \mathrm{~N}$ values between species. ONP = Starfish 1416 point, Olympic national park and SC = Davenport, Santa Cruz, CA. * indicates $\mathrm{p}<0.05$.

1417 Numbers above box plots indicate $n$ of specimens used in comparison. 